\title{
An update and beyond: key landscapes for conservation land cover and change monitoring, thematic and validation datasets for the African, Caribbean and Pacific regions
}

\author{
Zoltan Szantoi $^{1,2}$, Andreas Brink ${ }^{1}$, and Andrea Lupi ${ }^{1}$ \\ ${ }^{1}$ European Commission, Joint Research Centre, 21027 Ispra, Italy \\ ${ }^{2}$ Department of Geography and Environmental Studies, Stellenbosch University, \\ Stellenbosch 7602, South Africa \\ Correspondence: Zoltan Szantoi (zoltan.szantoi@remote-sensing-biodiversity.org) \\ Received: 22 March 2021 - Discussion started: 26 March 2021 \\ Revised: 18 June 2021 - Accepted: 5 July 2021 - Published: 6 August 2021
}

\begin{abstract}
Natural resources are increasingly threatened in the world. Threats to biodiversity and human wellbeing pose enormous challenges in many vulnerable areas. Effective monitoring and protection of sites with strategic conservation importance require timely monitoring, with a particular focus on certain land cover classes that are especially vulnerable. Larger ecological zones and wildlife corridors also warrant monitoring, as these areas are subject to an even higher degree of pressure and habitat loss as they are not "protected" compared to protected areas (national parks, nature reserves, etc.). To address such a need, a satellite-imagery-based monitoring workflow was developed to cover at-risk areas. The first phase of the programme covered a total area of $560442 \mathrm{~km}^{2}$ in sub-Saharan Africa. In this update, we remapped some of the areas using the latest satellite images available, and in addition we included some new areas to be mapped. Thus, in this version we have updated and mapped an additional $852025 \mathrm{~km}^{2}$ in the Caribbean, African and Pacific regions, involving up to 32 land cover classes. Medium- to high-spatial-resolution satellite imagery was used to generate dense time series data, from which the thematic land cover maps were derived. Each map and change map was fully verified and validated by an independent team to meet our strict data quality requirements. The independent validation datasets for each key landscape for conservation (KLC) are also described and presented here (all datasets presented are available at https://doi.org/10.1594/PANGAEA.931968; Szantoi et al., 2021a).
\end{abstract}

Key landscapes for conservation (MacKinnon et al., 2015) (KLCs) are defined as areas vast enough to sustain large wild animals (e.g. "big-five" game) within functioning biomes, that face pressure from various external factors such as poaching, agriculture expansion and urbanisation. Land use changes cause losses of both flora and fauna by altering wild animal movements, which can lead to decreases in population size over time (Di Minin et al., 2016; van der Meer, 2018). Livelihoods and wildlife in the Organisation of African, Caribbean and Pacific States (OACPS) that de- pend on natural resources face increasing pressure due to consumption of resources by the growing population of the regions; for example, the population of Africa is set to reach 2 billion by 2040 (MacKinnon et al., 2015; Di Minin et al., 2016). The representative, often transboundary, location types of the KLCs uniquely position them as benchmarks for their natural resource management in generating steady income for local residents while protecting their wildlife (MacKinnon et al., 2015). Benchmarking activities of this kind require highly accurate thematic land cover change (LCC) map products. Although LCC maps exist for many areas within the regions, the majority of products only cover 
protected areas, with some buffer zones (Szantoi et al., 2016). Moreover, continental and global mapping efforts have reported thematic accuracies of such land cover maps as between $67 \%$ and $81 \%$, with lower class accuracies reported in many cases (Mora et al., 2014). Differences in legends and unstandardised methods make these examples difficult to use for monitoring, modelling or change detection studies. In order to use various land cover (LC) and LCC products together (e.g. for modelling or policy-making), land cover class definitions should be standardised to avoid discrepancies in understanding thematic classes. Not all users (international organisations, national governments, civil societies, researchers) have the capabilities to readjust such maps (Saah et al., 2020). To accommodate such diverse user profiles, a common processing scheme is employed, and the resulting datasets can be utilised through various platforms and systems. This work adopted the Land Cover Classification System (LCCS) of the Food and Agriculture Organization (FAO) of the United Nations (Di Gregorio, 2005), an internationally approved ISO standard. The datasets presented in this paper are produced as part of the Copernicus High Resolution Hot Spot Monitoring (C-HSM) activity of the Copernicus Global Land Service.

All C-HSM products feature the same thematic land cover legend and geometric accuracy and were processed and validated following the same methodology. All products, including the C-HSM data, are free and open to any user with guaranteed long-term maintenance and availability under the Copernicus licence.

Copernicus serves as an operational programme where data are produced on a continuous basis. This paper presents an update to four previously published (Szantoi et al., 2020b) land cover and change maps (Greater Virunga, Salonga, Upemba and Yangambi KLCs) covering $160281 \mathrm{~km}^{2}$ of terrestrial land area in sub-Saharan Africa (SSA) and six additional KLCs covering $691744 \mathrm{~km}^{2}$ in the OACPS regions. The datasets are based mainly on freely available mediumspatial-resolution data: Copernicus Sentinel-2 (S-2) data for maps after 2015 and United States Geological Survey Landsat 7 and Landsat 8 (LS7, LS8) data for maps before 2015. The exceptions are three areas (Caribbean, Timor-Leste, and W-Arly-Pendjari Complex (WAPOK)) where we used Centre national d'études spatiales SPOT (SP4, SP5, SP6) data, because S-2 and LS7-LS8 had limited coverage for the time period we mapped. Each of the KLCs was individually validated for both present and change data. The processing chain developed always involves preliminary data assessment for availability, pre- and post-processing, and fully independent quality verification and validation steps. For the latter, a second dataset (validation data) is presented. Several recent studies call for sharing of product validation datasets (Fritz et al., 2017; Tsendbazar et al., 2018), especially if a collection received financial support through government grants (Szantoi et al., 2020a). Accordingly, the validation datasets (LCLCC) associated with each of the KLCs are also shared.

\section{Study area}

The thematic datasets provided concentrate on sub-Saharan Africa, with additional KLCs in the Caribbean and Pacific regions. The areas were selected based on present and future pressures envisioned and predicted by MacKinnon et al. (2015) and the Biodiversity and Protected Areas Management (BIOPAMA) Programme (https://biopama.org, last access: 1 August 2021). In this second phase (Phase 2), 10 large areas totalling $852025 \mathrm{~km}^{2}$ were selected, mapped and/or updated, and validated (Fig. 1). These areas cover various ecosystems and are generally located in transboundary regions (Table 1, Fig. 1). We selected four previously mapped KLCs (Szantoi et al., 2020b) to be remapped: Salonga (CAF07) because of the less detailed initial mapping (LCCS dichotomous level only) and Greater Virunga (CAF02), Upemba (CAF11) and Yangambi because of site importance identified by the BIOPAMA Programme and the Delegation of the European Union to DR Congo.

\section{Data and method}

The production workflow for the entire process is shown in Fig. 2. Each stage is explained in detail in the sections below.

\subsection{Data collection and mapping guidelines}

Imagery from Landsat ETM+ and OLI at L1TP; Sentinel-2 at Level-1C; and SPOT 4, 5 and 6 at Level 1B was used in producing and updating the land cover and change maps. As we had previously developed a surface reflectance production chain in our workflow (Szantoi et al., 2020b), the L1TP (Landsat), Level-1C (Sentinel-2) and Level 1B (SPOT) data were further corrected for atmospheric conditions to produce such products for the classification phase. The atmospheric correction module was implemented based on the $6 \mathrm{~S}$ direct radiative transfer model for Landsat (Masek et al., 2006) and SPOT (Haifeng et al., 2010) and using the Sen2Cor processor (v2.8) based on the ATCOR model (Richter et al., 2012). The Shuttle Radar Topography Mission (SRTM, $30 \mathrm{~m}$ or $90 \mathrm{~m}$ ) digital elevation model was used to estimate the target height and slope, as well as the surface sun incidence angles to apply topographic correction. Based on the area's meteo-climatic conditions (climate profile and precipitation patterns), season-specific satellite image data were selected for each KLC (Table 1). Additionally, as satellite data were limited for some of the mapped areas, especially for the years 2000 and 2005, imagery was collected for a target year (e.g. 2000) \pm 3 years. In some cases, this was expanded to \pm 5 years or to where four cloud-free observations per pixel had been collected for the specified date and location. 


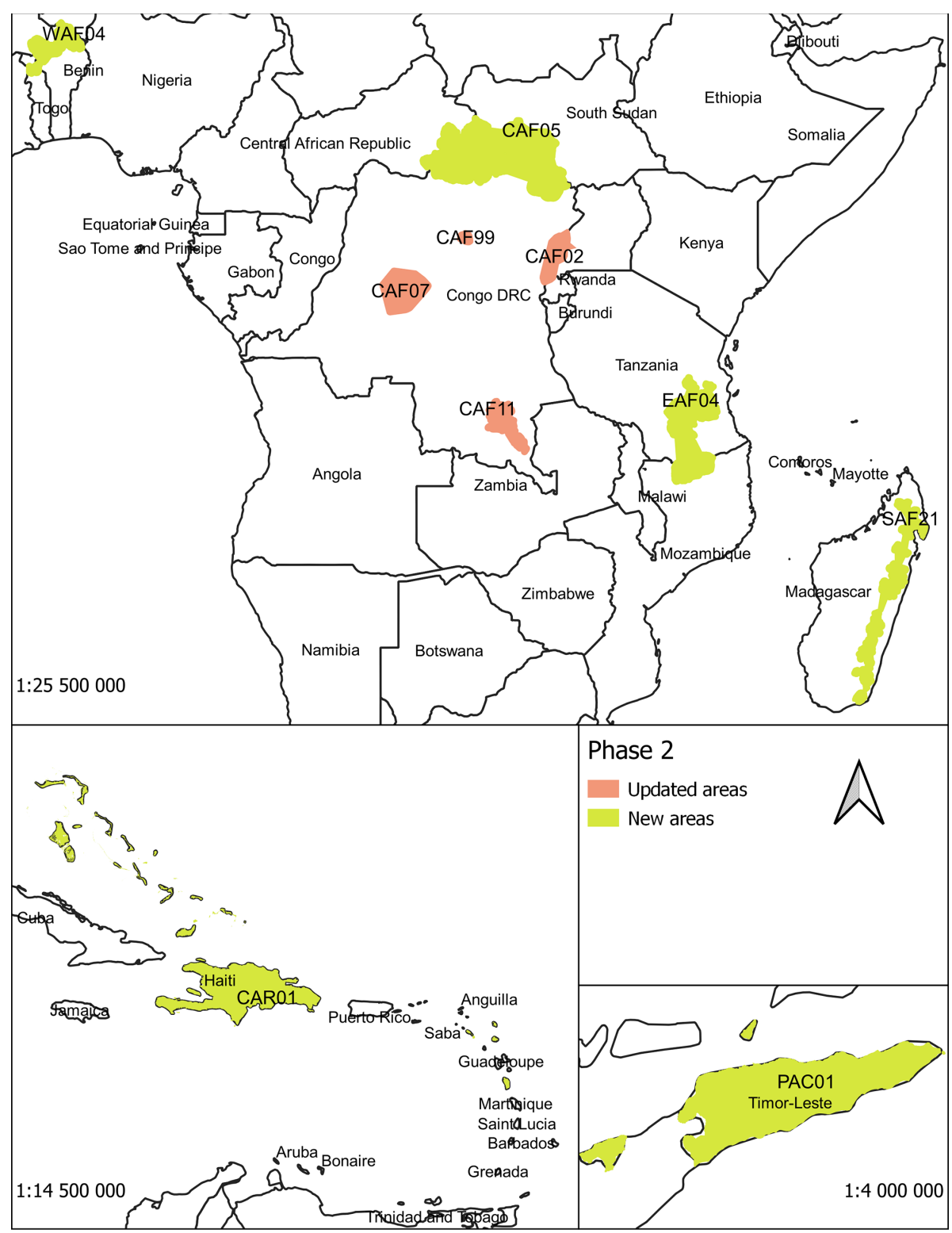

Figure 1. Spatial distribution of the key landscapes for conservation Phase 2 areas.

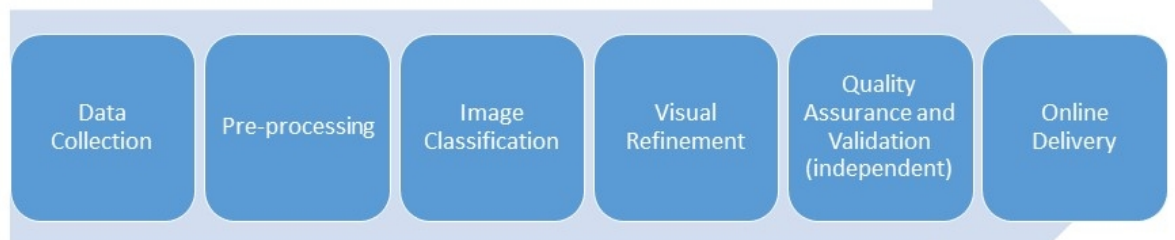

Figure 2. Overall production workflow. 
Table 1. Mapped key landscapes for conservation within Phase 2.

\begin{tabular}{|c|c|c|c|c|}
\hline KLC & Code & Ecoregion (Dinerstein et al., 2017) & Country & Area $\left(\mathrm{km}^{2}\right)$ \\
\hline \multicolumn{5}{|l|}{ Updated areas } \\
\hline Greater Virunga & CAF02 & $\begin{array}{l}\text { Albertine Rift montane forests } \\
\text { Victoria Basin forest-savanna }\end{array}$ & $\begin{array}{l}\text { DRC, Uganda, } \\
\text { Rwanda }\end{array}$ & 39062 \\
\hline Salonga & CAF07 & Central Congolian lowland forests & DRC & 66625 \\
\hline Upemba & CAF11 & $\begin{array}{l}\text { Central Zambezian wet miombo } \\
\text { woodlands }\end{array}$ & DRC & 47318 \\
\hline Yangambi & CAF99 & Northeastern Congolian lowland forests & DRC & 7276 \\
\hline \multicolumn{5}{|l|}{ New areas } \\
\hline Garamba & CAF05 & $\begin{array}{l}\text { East Sudanian savanna, Northern Congolian forest-savanna } \\
\text { mosaic, Northeastern Congolian lowland forests }\end{array}$ & $\begin{array}{l}\text { DRC, CAR, } \\
\text { South Sudan }\end{array}$ & 265976 \\
\hline Caribbean & CAR01 & $\begin{array}{l}\text { Windward Islands moist forests, Bahamian-Antillean man- } \\
\text { groves, Caribbean shrublands, Lesser Antillean dry forests, His- } \\
\text { paniolan moist forests, Enriquillo wetlands, Hispaniolan dry } \\
\text { forests, Hispaniolan pine forests, Bahamian pineyards }\end{array}$ & $\begin{array}{l}\text { AB, Bahamas, } \\
\text { Dominica, DR, } \\
\text { Haiti, SKN }\end{array}$ & 89883 \\
\hline Niassa-Selous & EAF04 & $\begin{array}{l}\text { Zambezian flooded grasslands, Eastern Miombo woodlands, } \\
\text { Eastern Arc forests, Northern Zanzibar-Inhambane coastal for- } \\
\text { est mosaic }\end{array}$ & $\begin{array}{l}\text { Tanzania, } \\
\text { Mozambique }\end{array}$ & 139163 \\
\hline Timor-Leste & PAC01 & Timor and Wetar deciduous forests & Timor-Leste & 14931 \\
\hline Madagascar & SAF21 & Madagascar lowland forests, Madagascar subhumid forests & Madagascar & 124012 \\
\hline WAPOK & WAF04 & West Sudanian savanna & $\begin{array}{l}\text { Ghana, Togo, } \\
\text { Benin, Burkina } \\
\text { Faso, Niger }\end{array}$ & 57776 \\
\hline
\end{tabular}

AB: Antigua and Barbuda; CAR: Central African Republic; DR: Dominican Republic; DRC: Democratic Republic of the Congo; SKN: Saint Kitts and Nevis.

\subsection{Land cover classification system}

All thematic maps were produced at both dichotomous and modular levels within the Land Cover Classification System (LCCS) developed by the FAO and the United Nations Environment Programme (Di Gregorio, 2005). The LCCS (ISO 19144-2) is a comprehensive hierarchical classification system that enables comparison of land cover classes regardless of geographic location or mapping date and scale (Di Gregorio, 2005). At the dichotomous level, the system distinguishes eight major LC classes. At the modular level, 32 LC classes were used (Table 2). For the Caribbean (CAR01), Timor-Leste (PAC01) and Madagascar (SAF21) KLCs, we included an additional land cover class not present in other KLC map products: "Not Inland Cover". Due to the specific location and the mapped areas (i.e. islands), this class is not present in the LCCS, and we only used it for our error assessment.

\subsection{Image classification}

Based on the imagery data (Appendix A), dense multitemporal time series (DMTs) were generated to allow proper char- acterisation of the temporal variability in the spectral features through various vegetation indices, aiding the LC class labelling process. The DMT for each KLC was based on the pre-processed and geometrically co-registered data, forming a geospatial datacube (Strobl et al., 2017). Three vegetation indices were calculated to aid the separation of terrestrial vs. aquatic (NDFI), vegetated vs. barren (SAVI) and evergreen vs. deciduous (NBR) vegetation areas. The indices are (per Landsat spectral band)

- normalised difference flood index (NDFI)

$$
\mathrm{NDFI}=\frac{(\mathrm{RED}-\mathrm{SWIR})}{(\mathrm{RED}+\mathrm{SWIR})}
$$

- soil-adjusted vegetation index (SAVI)

$$
\mathrm{SAVI}=\frac{1.5 \times(\mathrm{NIR}-\mathrm{RED})}{(\mathrm{NIR}+\mathrm{RED}+0.5)}
$$

- normalised burn ratio (NBR)

$$
\mathrm{NBR}=\frac{(\mathrm{NIR}-\mathrm{SWIR})}{(\mathrm{NIR}+\mathrm{SWIR})} .
$$


Table 2. Dichotomous and modular thematic land cover/use classes (MCD: mapcode dichotomous level; MCM: mapcode modular level; AG: aggregated classes for land cover change accuracy estimation; see Sect. 3.5 for additional information).

\begin{tabular}{|c|c|c|c|c|}
\hline Dichotomous level & $\mathrm{MCD}$ & Modular level & MCM & AG \\
\hline \multirow{8}{*}{$\begin{array}{l}\text { Cultivated and Managed Ter- } \\
\text { restrial Areas (A11) }\end{array}$} & \multirow{8}{*}{3} & $\begin{array}{l}\text { continuous large- to medium-sized field ( }>2 \text { ha) of tree crop cover: plan- } \\
\text { tation }\end{array}$ & 31 & 3 \\
\hline & & $\begin{array}{l}\text { continuous small-sized field ( }<2 \text { ha) of tree crop } \\
\text { cover: plantation }\end{array}$ & 32 & 3 \\
\hline & & $\begin{array}{l}\text { continuous large- to medium-sized field ( }>2 \text { ha) of tree crop cover: or- } \\
\text { chard }\end{array}$ & 33 & 3 \\
\hline & & $\begin{array}{l}\text { continuous small-sized field }(<2 \text { ha) of tree crop } \\
\text { cover: orchard }\end{array}$ & 34 & 3 \\
\hline & & continuous large- to medium-sized field ( $>2$ ha) of shrub crop & 55 & 3 \\
\hline & & continuous small-sized field ( $<2$ ha) of shrub crop & 56 & 3 \\
\hline & & continuous large- to medium-sized field ( $>2$ ha) of herbaceous crop & 59 & 3 \\
\hline & & continuous small-sized field ( $<2$ ha) of herbaceous crop & 60 & 3 \\
\hline \multirow{6}{*}{$\begin{array}{l}\text { Natural and Semi-Natural } \\
\text { Primarily Terrestrial Vegeta- } \\
\text { tion (A12) }\end{array}$} & \multirow{6}{*}{4} & continuous closed $(>70-60)$ trees & 77 & 77 \\
\hline & & continuous open general $(70 \%-60 \%)-(20 \%-10 \%)$ trees & 78 & 78 \\
\hline & & continuous closed to open $(100 \%-40 \%)$ shrubs & 112 & 4 \\
\hline & & continuous open $(40 \%-(20 \%-10 \%))$ shrubs & 116 & 4 \\
\hline & & continuous closed to open $(100 \%-40 \%)$ herbaceous vegetation & 148 & 4 \\
\hline & & continuous open $(40 \%-(20 \%-10 \%))$ herbaceous vegetation & 152 & 4 \\
\hline \multirow{4}{*}{$\begin{array}{l}\text { Cultivated Aquatic or Regu- } \\
\text { larly Flooded Areas (A23) }\end{array}$} & \multirow{4}{*}{6} & continuous large- to medium-sized field ( $>2 \mathrm{ha}$ ) of woody crops & 155 & 6 \\
\hline & & continuous small-sized field ( $<2$ ha) of woody crops & 156 & 6 \\
\hline & & continuous large- to medium-sized field ( $>2 \mathrm{ha}$ ) of graminoid crops & 159 & 6 \\
\hline & & continuous small-sized field $(<2 \mathrm{ha})$ of graminoid crops & 160 & 6 \\
\hline \multirow{6}{*}{$\begin{array}{l}\text { Natural And Semi-Natural } \\
\text { Aquatic or Regularly } \\
\text { Flooded Vegetation (A24) }\end{array}$} & \multirow{6}{*}{7} & closed $(>70 \%-60 \%)$ trees & 165 & 165 \\
\hline & & open general $(70 \%-60 \%)-(20 \%-10 \%)$ trees & 166 & 165 \\
\hline & & closed to open $(100 \%-40 \%)$ shrubs & 171 & 7 \\
\hline & & very open $(40 \%-(20 \%-10 \%))$ shrubs & 175 & 7 \\
\hline & & closed to open $(100 \%-40 \%)$ herbaceous vegetation & 178 & 7 \\
\hline & & very open $(40 \%-(20 \%-10 \%))$ herbaceous vegetation & 182 & 7 \\
\hline \multirow{2}{*}{$\begin{array}{l}\text { Artificial Surfaces and Asso- } \\
\text { ciated Area (B15) }\end{array}$} & \multirow{2}{*}{10} & built-up area & 184 & 184 \\
\hline & & non-built-up area & 185 & 185 \\
\hline Bare Areas (B16) & 11 & bare area & 11 & 11 \\
\hline \multirow{2}{*}{$\begin{array}{l}\text { Artificial Waterbodies, Snow } \\
\text { and Ice (B27) }\end{array}$} & \multirow{2}{*}{13} & artificial waterbodies (flowing) & 186 & 13 \\
\hline & & artificial waterbodies (standing) & 187 & 13 \\
\hline \multirow{4}{*}{$\begin{array}{l}\text { Natural Waterbodies, Snow } \\
\text { and Ice (B28) }\end{array}$} & \multirow{4}{*}{14} & natural waterbodies (flowing) & 190 & 14 \\
\hline & & natural waterbodies (standing) & 191 & 14 \\
\hline & & snow & 192 & 14 \\
\hline & & ice & 193 & 14 \\
\hline Not Inland Cover & 99 & not terrestrial cover & 999 & 999 \\
\hline
\end{tabular}


Imagery data (spectral bands and vegetation indices) were fed into the support vector machine (SVM) supervised classification model. The SVM classifier can handle data with high dimensionality and performs well when mapping heterogeneous areas, including vegetation community types (Szantoi et al., 2013). To produce the thematic maps, the minimum mapping unit concept used by Szantoi et al. (2016) was employed. Individual pixels (with corresponding land cover class information) were assigned to objects, where the minimum size of an object was set at $3 \mathrm{ha}\left(0.03 \mathrm{~km}^{2}\right)$, as a compromise between technical feasibility (pixel size) and the general size of the observable features (various land cover classes). However, classification errors (omission and commission of various classes) and false alarms (for land cover change) still occurred due to data availability (cloud cover, no data) and seasonal behaviour of the land cover (e.g. rapid foliage change). To correct these errors, expert human image interpretation skills and knowledge were applied, improving the outputs from the automated process.

\subsection{Land cover change detection}

Land cover change was interpreted as a categorical change in which one LC was replaced by another. Two examples of such a categorical change are the following: (1) conversion of cultivated and managed terrestrial areas (A11) into natural and semi-natural vegetation (A12) and (2) conversion of cultivated and managed terrestrial areas (A11) into artificial surfaces and associated areas (B15). LC change was identified based on detection of changes, employing the image-object overlay technique as a unit of analysis and hybrid change detection (Tewkesbury et al., 2015). This was achieved by applying layer arithmetic to locate changes such as (1) numerically compared spectral reflectance of the visible red and NIR bands and also derived indices such as NDFI, SAVI and NBR between the dates; and (2) classification to identify and label them (Lu et al., 2004).

LC changes were characterised as those lasting longer than a year and/or seasonal periodicity such as dry/wet seasons. Examples of longer-term changes include urban sprawl, large or small tree plantations replacing herbaceous crops, open or closed tree cover, or the creation of a reservoir. The LCC process applied followed the same steps for preprocessing Earth observation images as the LC method. From the pre-processed time series imagery, selected indices such as SAVI were calculated and statistically aggregated over defined periods to generate temporal features such as the maximum SAVI for a defined monitoring period. Once the changes were located based on temporal feature arithmetic, the changes identified were labelled by the SVM classifier. For the classification, we collected training and validation datasets for the corresponding monitoring periods using visual interpretation.

Finally, visual interpretation using expert knowledge was used to correct classification errors, i.e. real vs. misidentified
LC changes. When a within-object change was detected, the object was split. Similarly to the creation of the LC product, visual interpretation and subsequent refinement were important steps in producing accurate LCC polygons.

\subsection{Production of validation datasets}

The validation datasets (Table 3, Figs. 3 and 4) were individually created for each KLC. The validation datasets (points) were generated using a stratified random sampling procedure. This ensured sufficient estimation of all land cover and land cover change classes according to their frequency of occurrence. The following formula (Gallaun et al., 2015) was used to determine the minimum number of validation points (per class per KLC):

$n_{c}=\frac{p_{c\left(1-p_{c}\right)}}{\sigma_{c}^{2}} c=1, \ldots, L$,

where $n_{c}$ is the number of sampling units for class $c, p_{c}$ the estimated error rate for class $c, \sigma_{c}$ the accepted standard error of the error of commission for class $c$ and $L$ the number of classes.

In cases where classes covered smaller areas in total, additional sampling units were allocated according to Neyman optimal allocation, in order to minimise the variance of the estimator of the overall accuracy for the total sample size $[n]$ (Gallaun et al., 2015; Stehman, 2012):

$$
n_{c}=\frac{n N_{c} \sigma_{c}}{\sum_{k=1}^{L} N_{k} \sigma_{k}},
$$

where $n_{c}$ is the sample size for class $c, N_{c}$ the population size for class $c, \sigma_{c}$ the estimated error rate for class $c, L$ the number of classes, $N_{k}$ the population size for class $k$ and $\sigma_{k}$ the estimated error rate for class $k$.

At least two independent data analysts evaluated all accuracy points (blind and plausibility interpretation process) (Szantoi et al., 2021c). Some points were excluded from the accuracy statistics due to an error/disagreement during the evaluation procedure (Table 3 - "Number of points" for LC and LCC). The blind process attempted to interpret all validation points based on available ancillary data (i.e. higher-resolution imagery), without direct comparison to the LC/LCC maps generated. The plausibility process reviewed every point where the blind interpretation did not match the corresponding LC/LCC value (disagreement between the $\mathrm{LC} / \mathrm{LCC}$ data and the blind interpretation). After this review, the final validation reference was established.

Validation of the change maps (apart from CAF07, where we have assessed all the LCCS modular classes) aimed to assess the accuracy of the change detection. Thus, the following change categories were evaluated for those land cover changes (i.e. the accuracy assessments were performed based on the aggregated LCCS classes below) (the aggregated classes are also presented in Table 2): 
Table 3. Validation dataset attributes.

\begin{tabular}{|c|c|c|c|c|c|}
\hline \multirow[b]{2}{*}{$\begin{array}{l}\text { KLC } \\
\text { code }\end{array}$} & \multicolumn{2}{|c|}{ Land cover } & \multicolumn{2}{|c|}{ Land cover change } & \multirow[b]{2}{*}{$\begin{array}{r}\text { Number of } \\
\text { points }\end{array}$} \\
\hline & $\begin{array}{r}\text { Number of } \\
\text { classes }\end{array}$ & $\begin{array}{r}\text { Mapping } \\
\text { year }\end{array}$ & $\begin{array}{r}\text { Number of } \\
\text { classes }\end{array}$ & $\begin{array}{r}\text { Mapping } \\
\text { year }\end{array}$ & \\
\hline \multicolumn{6}{|c|}{ Updated areas } \\
\hline CAF02 & 27 & 2015 & 21 & 2019 & 2998 \\
\hline CAF07 & 17 & 2016 & 16 & 2019 & 3069 \\
\hline CAF11 & 23 & 2016 & 19 & 2019 & 3228 \\
\hline CAF99 & 17 & 2016 & 20 & 2019 & 2421 \\
\hline \multicolumn{6}{|c|}{ New areas } \\
\hline CAF05 & 24 & 2017 & $\begin{array}{l}17 \\
17\end{array}$ & $\begin{array}{l}2019 \\
2000\end{array}$ & $\begin{array}{l}4647 \\
7168\end{array}$ \\
\hline CAR01 & 29 & 2017 & 26 & 2000 & 4029 \\
\hline EAF04 & 26 & 2017 & 18 & 2000 & 3943 \\
\hline PAC01 & 28 & 2016 & $\begin{array}{l}26 \\
30 \\
28\end{array}$ & $\begin{array}{l}2000 \\
2005 \\
2010\end{array}$ & 4413 \\
\hline SAF21 & 29 & 2017 & 18 & 2000 & 3995 \\
\hline WAF04 & 24 & 2017 & 18 & 2000 & 3522 \\
\hline
\end{tabular}

- loss of natural vegetation - change from vegetation classes to any other class

- gain in natural vegetation - change from any class to vegetation classes

- woody natural vegetation (forest) cover loss - tree cover to any other class

- woody natural vegetation (forest) cover gain - change from any class to tree cover

- woody natural vegetation (forest) degradation - change from closed forest to open forest

- woody natural vegetation (forest) regeneration - change from open forest to closed forest

- cultivated and managed (cropland) extension - change from any class to cultivated classes

- artificial surface (human settlements) expansion change from any class to built-up class.

\section{Data quality assessment}

We updated some of the most critical landscapes (KLCs) due to various anthropogenic pressures for land cover change compared to the base maps we presented in Szantoi et al.
(2020). These KLCs were Greater Virunga (CAF02), Salonga (CAF07), Upemba (CAF11) and Yangambi (CAF99). The Salonga KLC (CAF07) was initially mapped at the dichotomous LCCS level (Table 2, eight land cover classes), but here we present both the base map (2016) and a change map (2019) mapped at the modular LCCS level. The new land cover and land cover change maps (CAF05, CAR01, EAF04, PAC01, SAF21 and WAF04) were all mapped at the modular level for land cover as well as for change.

\subsection{Technical validation}

Spatial, temporal and logical consistency was assessed using a procedure independent from the producer to determine the products' positional accuracy, the validity of data with respect to time (seasonality) and the logical consistency of the data (topology, attribution and logical relationships). A qualitative accuracy assessment was also performed throughout, using a systematic visual examination for (a) global thematic assessment, (b) expected size of polygons (minimum mapping unit), (c) seasonal effects and (d) spatial patterns (i.e. following correct edges).

The quantitative accuracy assessment (i.e. validation) results are shown in Table 4 (overall accuracies) and in the Appendix (thematic class accuracies per KLC, Appendix B). Generally, the programme aimed to achieve a minimum of $85 \%$ overall accuracy for each product (KLC) and a minimum of $75 \%$ thematic accuracy (producer's and user's accu- 

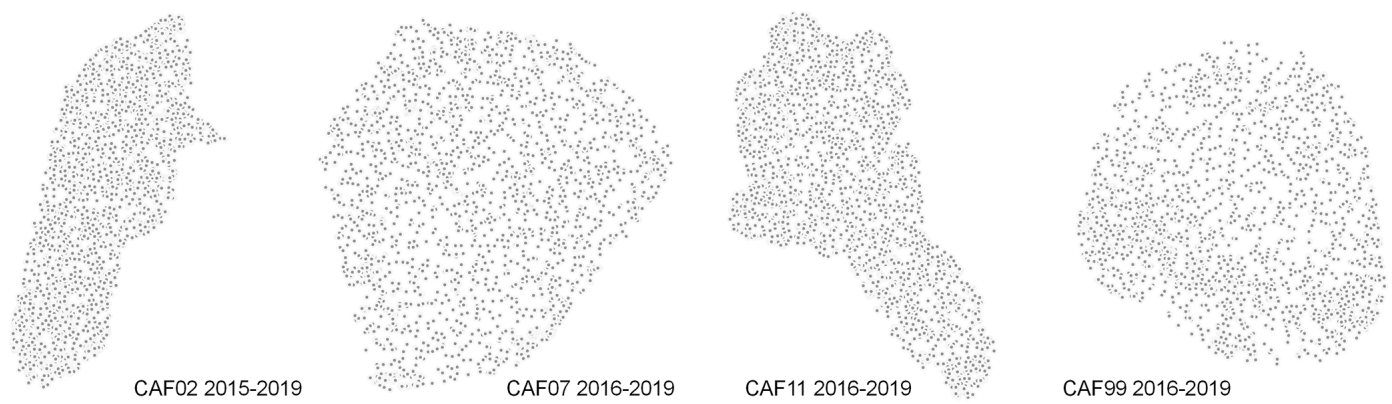

Figure 3. Spatial distribution of the validation datasets within the updated key landscapes for conservation.

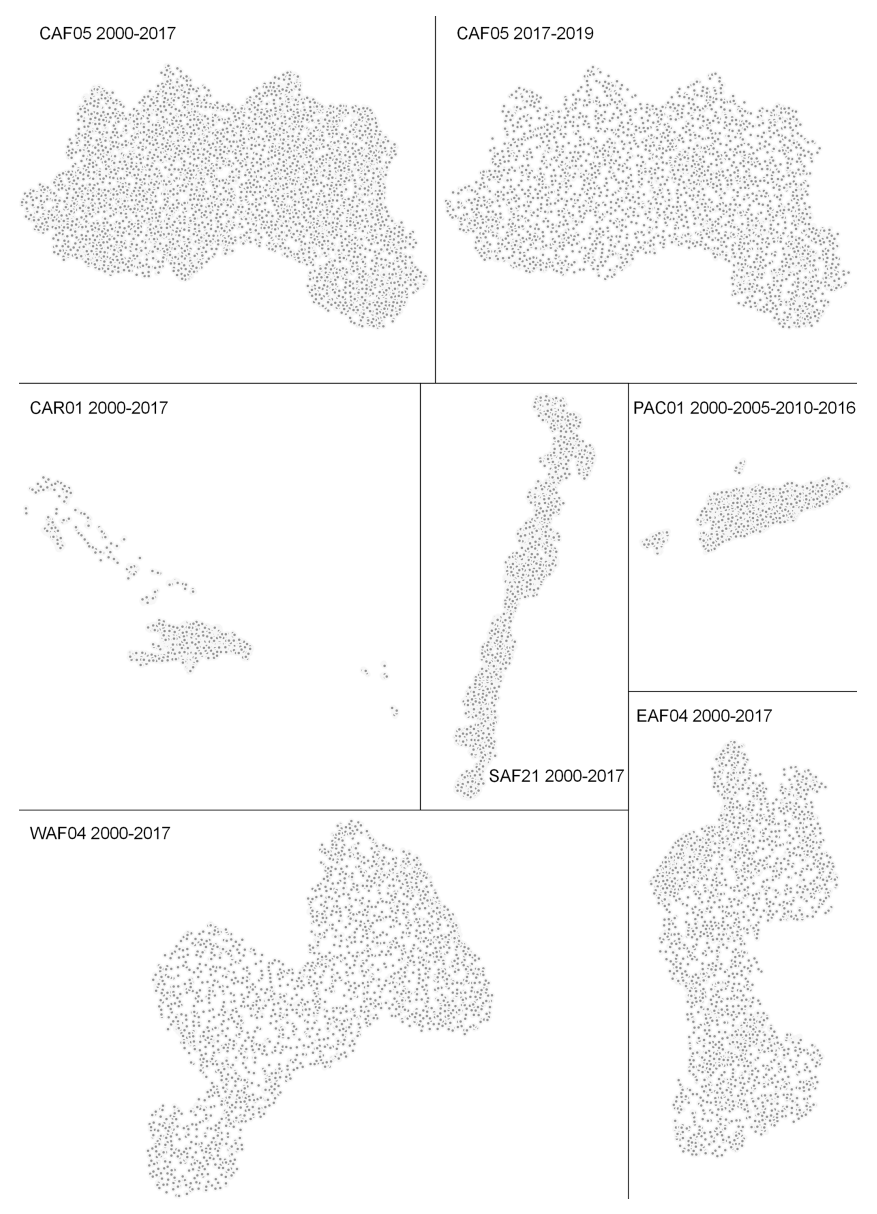

Figure 4. Spatial distribution of the validation datasets within the new key landscapes for conservation.

racy) for each class within each KLC. The land cover change accuracy should be $>72 \%$. The requirements for C-HSM map accuracy were established based on users' needs, as accurate LC/LCC map products are needed for many applications - such as ecosystem modelling (Grafius et al., 2016) and ecosystem valuation (Foody, 2015) - besides the general need for accurate representation of ground cover for policymaking. The Copernicus Global Land Service defines the
Table 4. Overall accuracies achieved for land cover mapping (\%).

\begin{tabular}{|c|c|c|c|c|}
\hline & \multicolumn{3}{|c|}{ Reference } & $\begin{array}{r}\text { Reference } \\
\text { date }\end{array}$ \\
\hline \multicolumn{5}{|c|}{ Updated thematic maps } \\
\hline CAF02 & 90.09 & 2015 & 99.38 & 2019 \\
\hline CAF02 & 90.09 & 2015 & 91.93 & 2001 \\
\hline CAF07 & 98.38 & 2016 & 98.36 & 2019 \\
\hline CAF11 & 95.27 & 2016 & 95.81 & 2019 \\
\hline CAF11 & 95.87 & 2016 & 95.81 & 2019 \\
\hline CAF99 & 98.51 & 2016 & 99.31 & 2019 \\
\hline CAF99 & 99.21 & 2016 & 99.31 & 2019 \\
\hline \multicolumn{5}{|c|}{ New thematic maps } \\
\hline \multirow[t]{2}{*}{ CAF05 } & 90.63 & 2015 & 91.63 & 2019 \\
\hline & 91.75 & 2015 & 92.35 & 2000 \\
\hline CAR01 & 92.55 & 2017 & 93.41 & 2000 \\
\hline EAF04 & 97.30 & 2017 & 97.80 & 2000 \\
\hline \multirow[t]{3}{*}{ PAC01 } & 91.28 & 2016 & 93.55 & 2000 \\
\hline & & & 93.26 & 2005 \\
\hline & & & 94.24 & 2010 \\
\hline SAF21 & 91.00 & 2017 & 92.30 & 2000 \\
\hline WAF04 & 97.20 & 2015 & 97.50 & 2000 \\
\hline
\end{tabular}

overall thematic accuracy of dynamic land cover mapping products as $>80 \%$ (Lang and Tychon, 2015). In exceptional cases, thematic accuracies may be lower than the threshold due to the difficulty of discriminating a particular class within a certain KLC.

Figure 5 shows the final LC and LCC products for the updated KLCs (CAF02, CAF07, CAF11 and CAF99), while Fig. 6 (CAR01, WAF04), Fig. 7 (CAF05, EAF04, SAF21) 


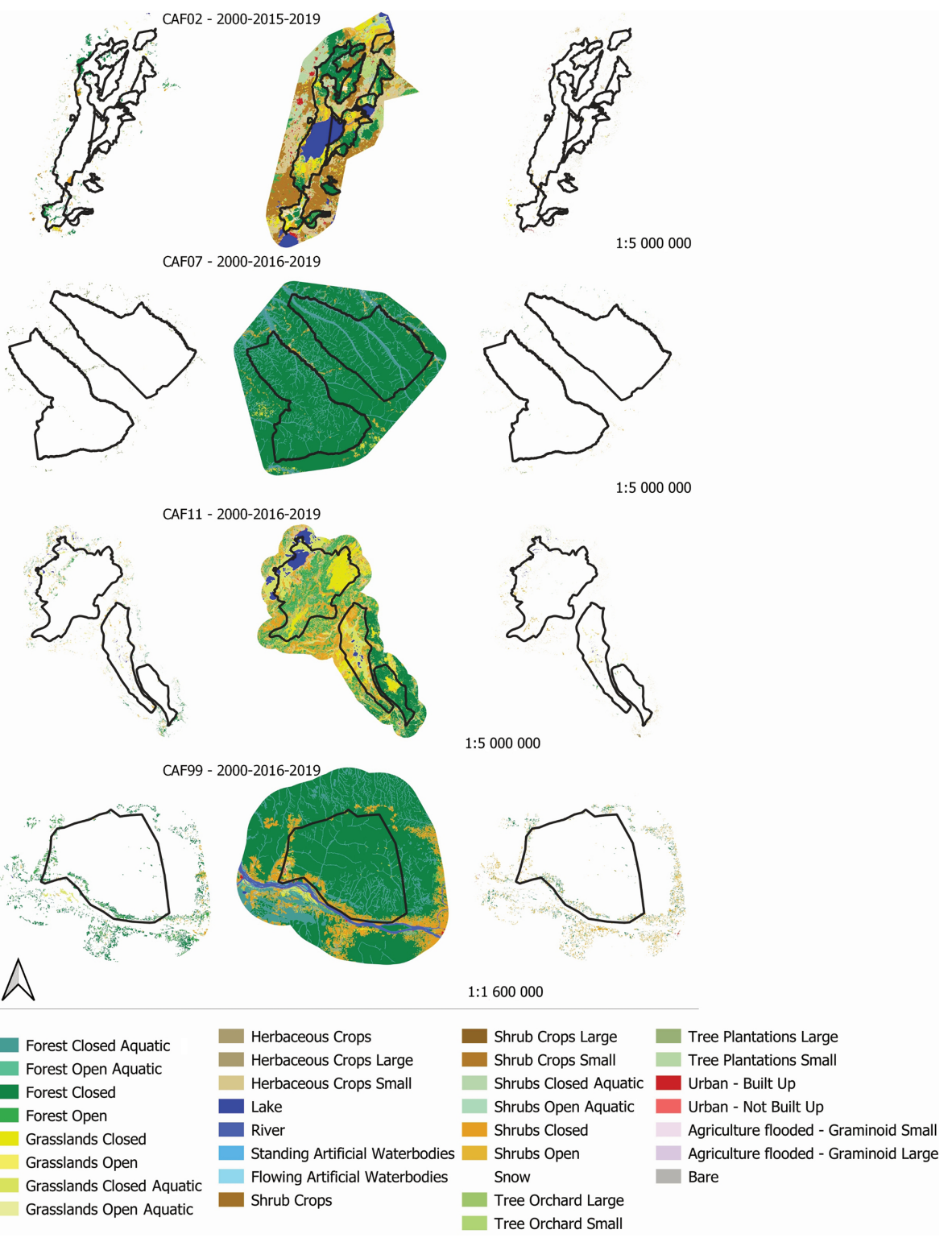

Figure 5. Key landscapes for conservation - modular classification level. The boundaries (black polygons) represent protected areas (IUCN category I-IV - UNEP-WCMC and IUCN, 2021) within the KLCs. Both land cover and land cover change maps are presented for each KLC. CAF02: Greater Virunga; CAF07: Salonga; CAF11: Upemba; CAF99: Yangambi. Year-2000 datasets are available in Szantoi et al. (2020b).

and Fig. 8 (PAC01) show the new LC and LCC products, all classified at the modular LCCS level. Some of the datasets presented in Fig. 5 have already been published in Earth System Science Data (Szantoi et al., 2020b): CAF02 year-2000 land cover change and year-2015 land cover maps; CAF07 year-2000 land cover change map; CAF11 year-2000 land cover change and year-2016 land cover maps; and CAF99 year-2000 land cover change and year-2016 land cover maps (for data access, please see the "Data availability" section).

\section{Discussion}

There is a direct relationship between population growth, agricultural expansion, energy demand and pressure on land (Lambin and Meyfroidt, 2011). With the current state of development, population increase and economic growth, a large portion of the sub-Saharan population is dependent on the remaining natural resources to meet their food and energy needs (Brink et al., 2012), while in the Caribbean (CAR01), urbanisation is putting pressure on natural resources (Nathaniel et al., 2021). In the case of Timor-Leste (PAC01), the peacebuilding process has been shaping the 


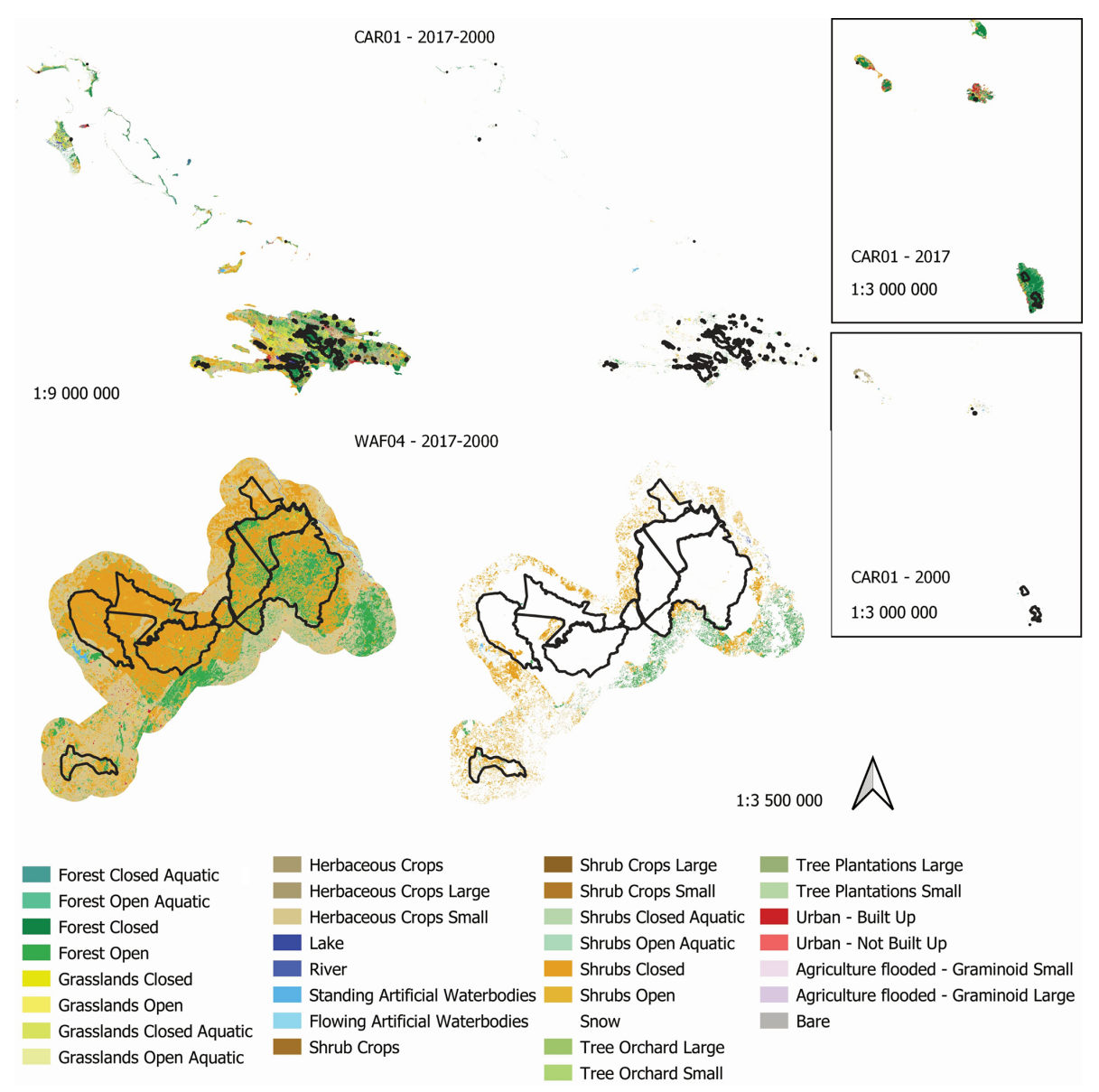

Figure 6. Key landscapes for conservation - modular classification level. The boundaries (black polygons) represent protected areas (IUCN category I-IV - UNEP-WCMC and IUCN, 2021) within the KLCs. Both land cover and land cover change maps are presented for each KLC. The inlets show the south-east part of the Caribbean KLC. CAR01: Caribbean; WAF04: WAPOK.

country's land cover and land use trends since 2006 (Ide et al., 2021). The demands of social and economic growth call for additional land, typically at the expense of previously untouched areas. Areas under protection (i.e. national parks) that remain well-preserved (see Figs. 5, 6 and 7) are often in close proximity to regions under excessive pressure. In particular, transboundary areas - such as the mapped WAPOK protected area - often highlight strong spatial heterogeneity in anthropogenic pressure between the different countries (Bühne et al., 2017). Such areas need very accurate monitoring and base maps, as provided through this work, especially as areas shared among countries are frequently not mapped with a common legend, if mapped at all. The KLC datasets presented can be used for continuous land cover and land use monitoring, evaluation of management practices and effectiveness, endowment for scientific guidance, habitat modelling, information dissemination, and capacity building in their corresponding countries and to manage natural resources such as forests, soil, biodiversity, ecosystem services and agriculture (Tolessa et al., 2017). Furthermore, regional climate change, biogeochemical and hydrologic models are currently capable of using high-resolution LC data for general predictions (Nissan et al., 2019) and for spatially focused predictions (i.e. Africa) (Sylla et al., 2016; Vondou and Haensler, 2017).

The validation datasets are independently collected and verified through a robust procedure. The entire product validation procedure is systematically repeatable, as it includes three separate components that are independently assessed: (1) the spatial, temporal and logical consistency component; (2) the qualitative accuracy component; and (3) the quantitative accuracy component. Each of these components can be performed separately, with the use of standardised informatics tools. In particular, the quantitative assessment validation component is structured with a sequence of steps in which interpretation of the LC classes is iterated when a cover (or change) is in doubt. Furthermore, a random quality check of the interpretation is performed on $10 \%$ of the interpretation points. Validation datasets can then be used for additional land cover mapping, creating spectral libraries and validating 


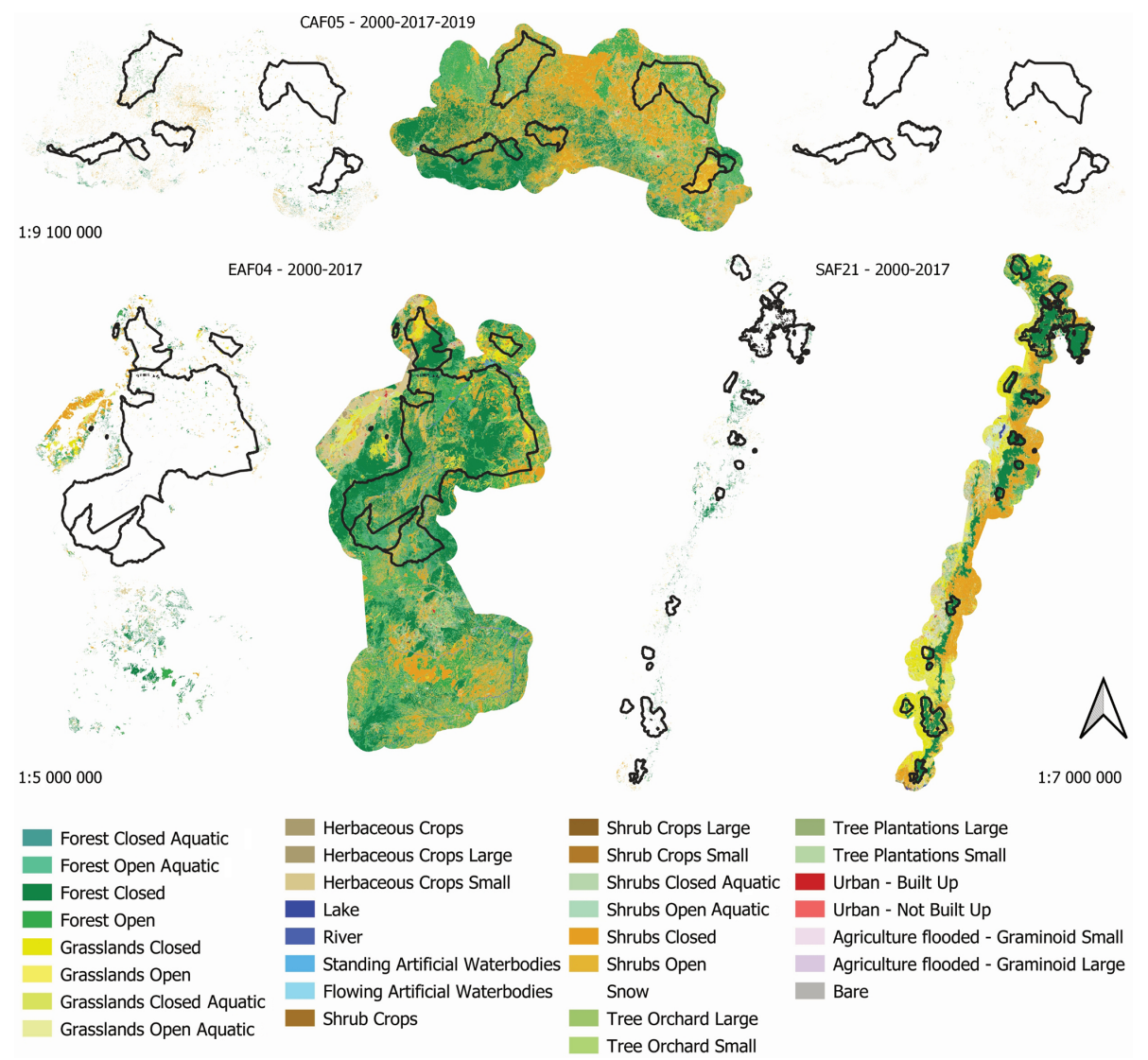

Figure 7. Key landscapes for conservation - modular classification level. The boundaries (black polygons) represent protected areas (IUCN category I-IV - UNEP-WCMC and IUCN, 2021) within the KLCs. Both land cover and land cover change maps are presented for each KLC. CAF05: Garamba; EAF04: Niassa-Selous; SAF21: Madagascar.

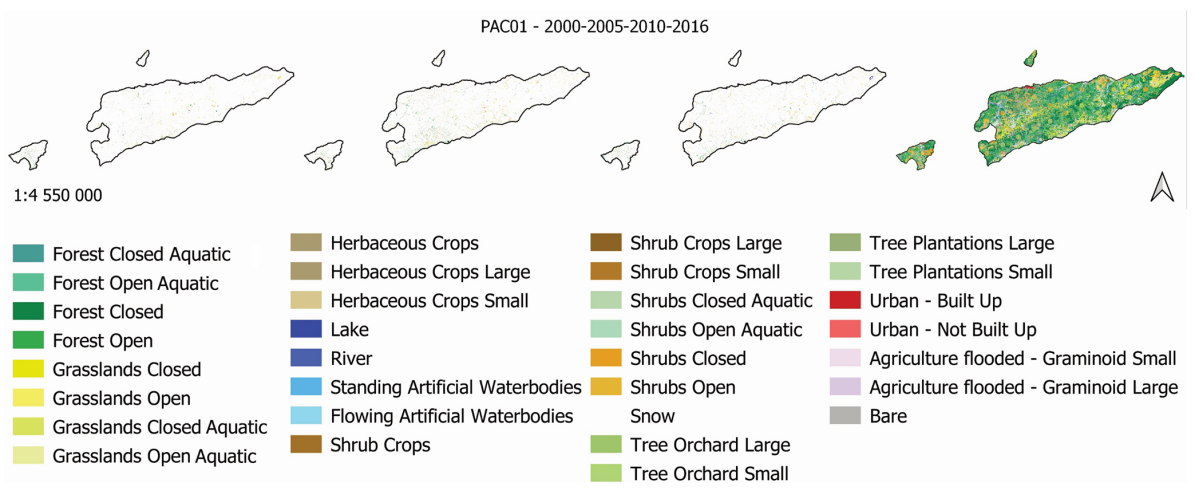

Figure 8. Timor-Leste Key Landscape for Conservation - modular classification level. The boundaries (black polygons) represent the country boundary. Both land cover and land cover change maps are presented for Timor-Leste.

other local, regional and global datasets. It is important that various land cover products can be used or compared against one another regardless of their geographic origins. Here, 10 land cover and land cover change maps are introduced for various areas in the OACPS where quality land cover products were previously missing (Marshall et al., 2017). All data were produced using the unified Land Cover Classification
System. The modular level of the LCCS can be applied to local scales thanks to its very detailed classes ( 32 were used here). 


\subsection{Drivers of change}

Geist and Lambin (2002) describe the human forces driving land cover changes as an interlinking of three key variables: expansion of agriculture, extraction of wood and development of infrastructure (urbanisation). The main land cover dynamic in sub-Saharan Africa can be explained not only by the first two variables but increasingly also by urbanisation, as in the other areas mapped (Caribbean, Timor-Leste) (Güneralp et al., 2017; Nathaniel et al., 2021; Hugo, 2019). Although the driving force behind the clearing of natural vegetation has traditionally been predominantly attributed to the expansion of new agricultural land (including investments in large-scale commercial agriculture) (Brink and Eva, 2009), firewood extraction and charcoal production are also key factors in forest, woodland and shrubland degradation throughout the region. This land cover dynamic is not just a byproduct of greater forces, such as logging for timber and agricultural expansion, but stems from a specific need to satisfy energy demand (European Commission, 2018); in fact, in sub-Saharan Africa, the main use of extracted wood is for energy production (Kebede et al., 2010). Although the region possesses a huge diversity of energy sources such as oil, gas, coal, uranium and hydropower, the local infrastructure and use of these commercial energy sources are still somewhat limited. Traditional sources of energy, in the form of firewood and charcoal, account for over $75 \%$ of total energy use in the region (Kebede et al., 2010). Efforts to meet population and economic demands in the OACPS, while preserving biodiversity and ecosystem functioning, require informed decision-making. The global component of the Copernicus Land Monitoring Service (Copernicus Global Land Service), in particular the High Resolution Hot Spot Monitoring activity, presents a unique opportunity for such information gathering.

\subsection{Sources of errors}

As the LCCS applied allows very detailed hierarchical classification, some classes can be difficult to distinguish from each other. This is especially true in Africa's vast and highly heterogeneous landscapes, where agricultural land use is mainly smallholder-based (i.e. very small plots), while shifting cultivation is mostly due to the lack of fertilisers and weak soil, leading to land abandonment. Landscapes are generally not composed of clearly fragmented and wellidentifiable cover formation. In this region, landscapes usually form a continuum of various cover (vegetation) formations, which may include different layers of tree, shrub and herbaceous vegetation. These variations, combined with differences in vegetation density (open vs. closed) and heights, make it challenging to assign classes. Moreover, some specific agricultural classes even distinguish the cultivation type, e.g. differentiating between fruit tree plantations and timber plantations. Thus, it is very difficult to discriminate be- tween such classes, and classification errors may be introduced. Apart from the land cover classification, errors could also be introduced due to climate-induced variability - such as leaf phenology, where deciduous vegetation may appear bare during a dry period (season). At a more general level, difficulties in distinguishing between aquatic or regularly flooded surfaces and terrestrial areas have been observed in certain KLCs, especially when flooded periods are short. The difficulty in interpreting some LC classes, as presented in the examples above, might introduce systematic over- and/or under-estimation of these particular covers in the accuracy statistics. The bias is reduced, for example, by giving higher weight to the errors in less represented LC classes depending on the ratio of ground control points collected per class, while the uncertainty in the LC class interpretation is quantified by calculating the confidence intervals (per class) in the statistics.

In the case of Timor-Leste (PAC01), it was particularly challenging to discriminate between evergreen and deciduous natural vegetation across the seasonal variations.

Another specific source of error can be identified for the Caribbean KLC (CAR01), where the area consists of a vast complex of small islands (i.e. keys) and archipelagos that include large areas of coastal swamps. In these regions, the connection of the coastal inland water surfaces with the open sea is often very difficult to identify. Consequently, there are areas where assignment of the water surface classes was ambiguous with respect to the open sea, which would result in the exclusion of areas from the map.

\subsection{Current and future use of datasets}

The C-HSM datasets have been widely used by policymakers (OACPS and European partners) to help identify areas prone to change due to human activities. For example, COFED (Support Unit for the National Authorising Officer of the European Development Fund) in the DRC - the EEAS (European External Action Service) in the DRC - manages an envelope of EUR 120 million allocated for five protected areas in the DRC (Virunga, Garamba, Salonga, Upemba and the Yangambi biosphere), where they use the C-HSM products for planning and for investment strategies (e.g. hydropower). Thus, the EEAS requested updates in terms of land cover changes for 2019 for the above-mentioned protected areas, which we present in this study. Another example is from West Africa, where non-governmental organisations (NGOs, e.g. the Wild Chimpanzee Foundation), public benefit enterprises (e.g. the German Society for International Cooperation - GIZ) and national authorities (e.g. l'Office Ivoirien des Parcs et Réserves - OIPR) use the data to identify areas under pressure from agriculture (cocoa, oil palm, rubber and coconut) and human-wildlife conflicts in Côte d'Ivoire, Ghana and Liberia. Additional areas (CAR01, PAC01) mapped and presented in this study can be used to help projects (e.g. BIOPAMA) and countries to improve 
management and governance of their biodiversity and natural resources.

\section{Data availability}

The data are provided in a shapefile (*.shp) format, polygon geometry for the land cover and change datasets, and point geometry for the validation datasets. The data presented are in the World Geodetic System 1984 geographic coordinate system (GCS) (EPSG:4326) and its datum (EPSG:6326). The validation data, besides using the same GCS, also use the Africa Albers equal-area conic (EPSG:102022) projected coordinate system.

Apart from CAF05 and PAC01, each KLC is described by two polygon vector layers: a land cover (LC) layer and a land cover change (LCC) layer. In the case of CAF05, we present three layers (2000 and 2019 as LCC and 2017 as LC), and for PAC01 we present four layers (2000, 2005 and 2010 as LCC and 2016 as LC). The LC layer is always a wall-to-wall map, covering the entire area of interest (AOI). The LC temporal reference for the project is the year 2016, although for each area the actual "mapping year" is noted in the file name (e.g. CAF05_2017); this generally refers to the year from which the largest number of satellite images were used for the classification. The LCC layer provides partial coverage of the AOI, as it contains only the areas (polygons) where thematic change occurred compared to the LC layer. The LCC temporal reference is the year $2000( \pm 3$ years $)$, noted in the file name (e.g. CAF05_2000).

Each LC and LCC shapefile comes with its corresponding attribute table, where two or three attributes are present: [map_codeA] - dichotomous class, [map_code] - modular class, [class_name] - corresponding modular class name.

Each of the 10 areas has been quantitatively validated using a spatially specific point dataset. These datasets were generated through the method described in Sect. 3.5, and each point was used to verify the correctness of the LCLCC maps. The corresponding data in the attribute table are LC - [plaus201X] and LCC - [plaus200X] or [plaus201X]. Both [plaus201X] and [plaus200X] attributes refer to the most detailed classification level attributes (map_code or map_codeA) present in the LC and LCC datasets (shapefiles). Some of the validation datasets contain only attributes of the aggregated classes, as described in Sect. 3.2; those attributes are named as [plaus201Xr, plaus200Xr]. The plaus201X and plaus200X attributes refer to the year the validation sets represent, as these can be different among KLCs; the exact year is always noted in the column names (e.g. plaus2000, plaus2016).

The naming of all attributes follows the same structure for all data. Please see the details in Appendix B.

The datasets are available for download, as a complete package (all datasets together) or individually as source datasets (each KLC), from
https://doi.org/10.1594/PANGAEA.931968 (Szantoi et al., 2021a) and https://doi.org/10.5281/zenodo.4621375 (Szantoi et al., 2021b).

Besides archiving the datasets at Zenodo and PANGAEA with corresponding digital object identifiers, the Copernicus High Resolution Hot Spot Monitoring (C-HSM) website (https://land.copernicus.eu/global/hsm, last access: 1 June 2021) provides open access to all the land cover and land cover change maps presented in this article, as well as technical reports and on-the-fly statistics.

\section{Conclusions}

The C-HSM component is part of the Copernicus Global Land Service, which produces near-real-time biophysical variables at medium scale, globally. By contrast, the C-HSM activity is an on-demand component that addresses specific user requests in the field of sustainable management of natural resources. The products presented here provide the second set of standardised land cover and land cover change datasets for $10 \mathrm{KLCs}$ in the African, Caribbean and Pacific regions, with their corresponding validation datasets. The geographic distribution covers the tropical and subtropical regions of west, central and south-eastern Africa, as well as a large part of the Caribbean region and Timor-Leste in the $\mathrm{Pa}$ cific region. The most recent land cover change may be periodically reassessed for selected already-mapped KLCs in order to generate longer-term time series land cover dynamics information, as is the case for some of the data presented here (CAF02, CAF07, CAF11 and CAF99 - see the original LC/LCC data in Szantoi et al., 2020b). Although this is not done systematically but on specific customer requests, the C-HSM service encourages stakeholder cooperation and provides capacity-building workshops around the globe. Inperson training events provide an opportunity for new and existing users to learn how to use and interpret data, operate the web information system, and easily assess recent land cover change data using Sentinel-2 image mosaics. Here, we provide very high quality products, which can be used directly as base maps and for policy decisions, as well as for comparison and/or evaluation of other land cover products or the implementation of validation datasets for training and validation purposes.

Finally, the service has a high degree of confidence that the data presented here (and in the previous phase, Szantoi et al., 2020b) are of the highest quality, regularly reaching above $90 \%$ overall accuracy. This is guaranteed by a rigorous and independent production and validation mechanism and feedback loop, which does not stop until the required overall and per-class accuracy levels are reached.

In accordance with the general European Commission open-access policy for the Copernicus Programme, the data are distributed freely to any user, through a dedicated website (https://land.copernicus.eu/global/hsm, last access: 1 June 
2021). This interactive online information system allows access to browse, analyse and download the data, including the accuracy assessment information. 
Appendix A

Table A1. Satellite data collecting period and type used for LC and LCC mapping. Date format is month/year.

\begin{tabular}{lllllll}
\hline KLC & LC map & Data period & Data type* $^{*}$ & LCC map & Data period & Data type $^{*}$ \\
\hline CAF02 & 2015 & $07 / 2013-10 / 2016$ & LS8 & 2019 & $01 / 2019-12 / 2019$ & S-2 \\
CAF07 & 2016 & $05 / 2013-10 / 2016$ & LS8 & 2019 & $01 / 2019-01 / 2020$ & S-2 \\
CAF11 & 2016 & $01 / 2015-06 / 2016$ & LS8 & 2019 & $01 / 2019-10 / 2019$ & S-2 \\
CAF99 & 2016 & $03 / 2014-11 / 2016$ & LS8 & 2019 & $02 / 2019-12 / 2019$ & S-2 \\
CAF05 & 2017 & $12 / 2014-01 / 2018$ & LS8 & 2019 & $02 / 2019-11 / 2019$ & S-2 \\
& & & & 2000 & $11 / 1999-01 / 2003$ & LS7 \\
CAR01 & 2017 & $05 / 2016-12 / 2017$ & S-2 & 2000 & $02 / 1999-11 / 2004$ & SP4, LS7 \\
EAF04 & 2017 & $04 / 2016-10 / 2017$ & S-2 & 2000 & $07 / 1999-06 / 2002$ & LS7 \\
PAC01 & 2016 & $12 / 2015-11 / 2016$ & S-2 & 2000 & $04 / 2001-11 / 2002$ & SP4, SP5 \\
& & & & 2005 & $04 / 2003-12 / 2007$ & SP5 \\
& & & & 2010 & $01 / 2008-10 / 2012$ & SP5, SP6 \\
SAF21 & 2017 & $06 / 2016-11 / 2017$ & S-2 & 2000 & $10 / 1999-12 / 2002$ & LS7 \\
WAF04 & 2017 & $11 / 2016-03 / 2018$ & S-2 & 2000 & $09 / 1998-06 / 2003$ & SP4, SP5 \\
\hline
\end{tabular}

* S-2: Sentinel 2; LS7: Landsat 7; LS8: Landsat 8; SPOT 4: SP4; SPOT 5: SP5; SPOT 6: SP6.

\section{Appendix B}

Table B1. Thematic class accuracies per KLC. Accuracy parameters are in percent; classes with fewer than 15 samples were not included in the overall accuracy calculation. Accuracy results are presented at the aggregated as well as at the modular LCCS levels, depending on the type of mapping (land cover map - modular, land cover change map - aggregated). Class: corresponding class (see Table 2 modular (MCM) or aggregated (AG) map code); PA: producer's accuracy; UA: user's accuracy; NoRP: number of reference points.

\begin{tabular}{|c|c|c|c|c|c|c|}
\hline \multirow[b]{3}{*}{ Class } & \multicolumn{6}{|c|}{ CAF02 (aggregated) } \\
\hline & \multicolumn{3}{|c|}{2015} & \multicolumn{3}{|c|}{2019} \\
\hline & PA & UA & NoRP & PA & UA & NoRP \\
\hline 3 & 99.7 & 99.7 & 1277 & 99.7 & 99.6 & 1243 \\
\hline 4 & 98.8 & 97.7 & 510 & 98.8 & 98.2 & 541 \\
\hline 6 & 0 & 0 & 0 & 0 & 0 & 0 \\
\hline 7 & 100 & 99 & 120 & 100 & 99 & 148 \\
\hline 11 & 96.8 & 93.4 & 28 & 100 & 93.3 & 20 \\
\hline 14 & 100 & 100 & 219 & 100 & 100 & 175 \\
\hline 77 & 100 & 99.9 & 648 & 99.9 & 100 & 508 \\
\hline 78 & 92.6 & 100 & 133 & 92.3 & 98.4 & 217 \\
\hline 165 & 100 & 100 & 3 & 100 & 100 & 2 \\
\hline 166 & 100 & 100 & 5 & 100 & 100 & 2 \\
\hline 184 & 99.9 & 100 & 52 & 100 & 99.9 & 129 \\
\hline 185 & 100 & 100 & 2 & 100 & 100 & 10 \\
\hline
\end{tabular}


Table B1. Continued.

\begin{tabular}{|c|c|c|c|c|c|c|c|c|c|}
\hline \multirow[b]{3}{*}{ Class } & \multicolumn{9}{|c|}{ CAF05 (aggregated) } \\
\hline & \multicolumn{3}{|c|}{2000} & \multicolumn{3}{|c|}{2015} & \multicolumn{3}{|c|}{2019} \\
\hline & PA & UA & NoRP & PA & UA & NoRP & PA & UA & NoRP \\
\hline 3 & 92.8 & 76.9 & 396 & 85 & 92.4 & 249 & 85.9 & 89.6 & 211 \\
\hline 4 & 91.4 & 95 & 2957 & 93.5 & 91.4 & 1720 & 93.4 & 91.3 & 1764 \\
\hline 7 & 98.7 & 84.2 & 317 & 82.5 & 87.3 & 150 & 82.5 & 87.3 & 149 \\
\hline 11 & 98.3 & 93.5 & 59 & 83.8 & 100 & 10 & 83.8 & 100 & 10 \\
\hline 13 & 100 & 100 & 8 & 100 & 100 & 14 & 100 & 100 & 15 \\
\hline 14 & 95.4 & 93.9 & 96 & 99.9 & 100 & 22 & 99.9 & 100 & 21 \\
\hline 77 & 94.1 & 96.4 & 1956 & 94.8 & 96.2 & 1399 & 94.6 & 96.2 & 1283 \\
\hline 78 & 90.7 & 83 & 1205 & 85.7 & 86.2 & 917 & 85.6 & 86.2 & 949 \\
\hline 165 & 0 & 0 & 0 & 0 & 0 & 1 & 0 & 0 & 1 \\
\hline 166 & 100 & 83.7 & 41 & 100 & 100 & 1 & 100 & 100 & 1 \\
\hline 184 & 96.8 & 94.3 & 88 & 82.7 & 97.6 & 92 & 81.6 & 97.4 & 155 \\
\hline 185 & 100 & 23.1 & 9 & 100 & 93.2 & 70 & 94.9 & 94 & 87 \\
\hline
\end{tabular}

Table B1. Continued.

\begin{tabular}{|c|c|c|c|}
\hline \multirow[b]{3}{*}{ Class } & \multicolumn{3}{|c|}{ CAF05 (all classes - LC map) } \\
\hline & \multicolumn{3}{|c|}{2015} \\
\hline & $\mathrm{PA}$ & UA & NoRP \\
\hline 11 & 98.3 & 93.5 & 59 \\
\hline 31 & 100 & 99.9 & 127 \\
\hline 32 & 5.9 & 92.3 & 14 \\
\hline 34 & 100 & 100 & 1 \\
\hline 56 & 90 & 92.4 & 67 \\
\hline 59 & 0 & 0 & 0 \\
\hline 60 & 85.1 & 83 & 209 \\
\hline 77 & 95.1 & 95.8 & 1954 \\
\hline 78 & 89.9 & 82.8 & 1184 \\
\hline 112 & 88.8 & 93.2 & 2355 \\
\hline 116 & 81.2 & 74.9 & 285 \\
\hline 148 & 72.6 & 84.2 & 215 \\
\hline 152 & 94.4 & 93.6 & 9 \\
\hline 165 & 0 & 0 & 0 \\
\hline 166 & 100 & 85.1 & 40 \\
\hline 171 & 98.4 & 73.7 & 82 \\
\hline 175 & 98.8 & 95.6 & 75 \\
\hline 178 & 98.1 & 87.2 & 152 \\
\hline 182 & 87.5 & 28 & 8 \\
\hline 184 & 95.1 & 95.8 & 161 \\
\hline 185 & 100 & 100 & 50 \\
\hline 187 & 100 & 100 & 8 \\
\hline 190 & 95.4 & 94 & 80 \\
\hline 191 & 100 & 95.8 & 23 \\
\hline
\end{tabular}

Table B1. Continued.

\begin{tabular}{|c|c|c|c|c|c|c|c|}
\hline \multicolumn{8}{|c|}{ CAF07 (all classes - LC/LCC map) } \\
\hline \multicolumn{4}{|c|}{2016} & \multicolumn{4}{|c|}{2019} \\
\hline Class & PA & UA & NoRP & Class & PA & UA & NoRP \\
\hline 11 & 100 & 100 & 2 & 11 & 100 & 100 & 2 \\
\hline 31 & 96.6 & 83.6 & 53 & 31 & 95.9 & 84.2 & 52 \\
\hline 32 & 96.4 & 66.7 & 3 & 32 & 97.6 & 33.3 & 4 \\
\hline 56 & 95.1 & 77.5 & 91 & 56 & 87.8 & 75.8 & 112 \\
\hline 60 & 91.3 & 89.8 & 102 & 60 & 91.3 & 72.6 & 89 \\
\hline 77 & 98.4 & 99.8 & 1605 & 77 & 98.5 & 99.8 & 1524 \\
\hline 78 & 82.7 & 92.7 & 98 & 78 & 90.1 & 94.9 & 124 \\
\hline 112 & 89.5 & 86.1 & 231 & 112 & 89 & 88.6 & 297 \\
\hline 116 & 96.2 & 96.8 & 61 & 116 & 82.8 & 90 & 30 \\
\hline 148 & 99.8 & 97.4 & 134 & 148 & 99.4 & 97.5 & 144 \\
\hline 165 & 99.3 & 92.3 & 386 & 152 & 0 & 0 & 0 \\
\hline 166 & 31.6 & 75 & 19 & 165 & 99.3 & 92.3 & 379 \\
\hline 171 & 94.1 & 94.3 & 54 & 166 & 31.6 & 47.2 & 19 \\
\hline 175 & 0 & 0 & 2 & 171 & 94.5 & 94 & 65 \\
\hline 178 & 100 & 85 & 51 & 175 & 50 & 100 & 4 \\
\hline 184 & 83.1 & 90.4 & 77 & 178 & 92.1 & 85.4 & 38 \\
\hline 190 & 87.8 & 93.8 & 77 & 184 & 81 & 90.5 & 87 \\
\hline \multirow[t]{2}{*}{191} & 100 & 100 & 22 & 190 & 87.7 & 92.6 & 76 \\
\hline & & & & 191 & 100 & 100 & 22 \\
\hline
\end{tabular}


Table B1. Continued.

\begin{tabular}{|c|c|c|c|c|c|c|c|c|c|}
\hline \multirow[b]{3}{*}{ Class } & \multicolumn{9}{|c|}{ CAF11 (aggregated) } \\
\hline & \multicolumn{3}{|c|}{2000} & \multicolumn{3}{|c|}{2016} & \multicolumn{3}{|c|}{2019} \\
\hline & $\mathrm{PA}$ & UA & NoRP & PA & UA & NoRP & $\mathrm{PA}$ & UA & NoRP \\
\hline 3 & 98.7 & 92.8 & 339 & 92.9 & 95.1 & 201 & 93 & 96.2 & 272 \\
\hline 4 & 99.3 & 93.8 & 1169 & 99.2 & 92.4 & 1099 & 99.2 & 92.2 & 999 \\
\hline 6 & 100 & 14.4 & 2 & 42.4 & 100 & 33 & 42.5 & 100 & 33 \\
\hline 7 & 96.9 & 99.2 & 614 & 97.8 & 96.5 & 373 & 97.9 & 96.8 & 372 \\
\hline 11 & 100 & 96.7 & 30 & 0 & 0 & 0 & 0 & 0 & 0 \\
\hline 14 & 98.7 & 99.9 & 275 & 99.8 & 99.4 & 120 & 100 & 99.8 & 111 \\
\hline 77 & 94.5 & 95.6 & 529 & 90.5 & 98.9 & 515 & 90.4 & 98.8 & 430 \\
\hline 78 & 92.6 & 97.7 & 597 & 95 & 98.4 & 711 & 94.8 & 98.3 & 760 \\
\hline 165 & 79.4 & 96.3 & 79 & 77.1 & 100 & 7 & 77 & 100 & 5 \\
\hline 166 & 98.7 & 99.2 & 47 & 99.8 & 99.3 & 12 & 99.8 & 99.2 & 11 \\
\hline 184 & 100 & 95.8 & 87 & 99.9 & 94.6 & 81 & 100 & 94.9 & 157 \\
\hline 185 & 100 & 95.4 & 17 & 100 & 100 & 76 & 93.8 & 100 & 78 \\
\hline
\end{tabular}

Table B1. Continued.

\begin{tabular}{lrrr}
\hline \multicolumn{4}{c}{ CAF11 (all classes - LC map) } \\
\hline \multicolumn{4}{c}{2015} \\
\hline Class & PA & UA & NoRP \\
\hline 11 & 100 & 100 & 30 \\
32 & 100 & 100 & 26 \\
34 & 0 & 0 & 0 \\
56 & 69.9 & 100 & 1 \\
59 & 92.4 & 99.1 & 74 \\
60 & 97.3 & 97.1 & 339 \\
77 & 94.6 & 95.2 & 488 \\
78 & 92.4 & 97.1 & 534 \\
112 & 96.8 & 86.9 & 441 \\
116 & 97.7 & 94.3 & 289 \\
148 & 98.5 & 97.1 & 325 \\
152 & 0 & 0 & 0 \\
160 & 100 & 100 & 3 \\
165 & 79.1 & 96.2 & 78 \\
166 & 96.9 & 99.2 & 46 \\
171 & 75 & 92.7 & 74 \\
175 & 56.8 & 98.6 & 72 \\
178 & 97.9 & 98 & 411 \\
182 & 95 & 95 & 20 \\
184 & 100 & 98.9 & 167 \\
185 & 100 & 100 & 75 \\
190 & 87.9 & 98.2 & 90 \\
191 & 99.8 & 100 & 202 \\
\hline & & &
\end{tabular}


Table B1. Continued.

\begin{tabular}{|c|c|c|c|c|c|c|c|c|c|}
\hline \multirow[b]{3}{*}{ Class } & \multicolumn{9}{|c|}{ CAF99 (aggregated) } \\
\hline & \multicolumn{3}{|c|}{2000} & \multicolumn{3}{|c|}{2016} & \multicolumn{3}{|c|}{2019} \\
\hline & $\mathrm{PA}$ & UA & NoRP & $\mathrm{PA}$ & UA & NoRP & PA & UA & NoRP \\
\hline 3 & 91.6 & 98.9 & 431 & 85.9 & 98 & 241 & 86.2 & 98.7 & 193 \\
\hline 4 & 92.4 & 92.1 & 417 & 98.4 & 96.4 & 397 & 99.5 & 97.5 & 452 \\
\hline 7 & 100 & 97.8 & 231 & 99.8 & 88 & 72 & 94.7 & 88.8 & 76 \\
\hline 14 & 100 & 100 & 175 & 100 & 100 & 108 & 100 & 100 & 109 \\
\hline 77 & 99 & 99.2 & 905 & 99.7 & 99.9 & 1139 & 99.7 & 99.9 & 1098 \\
\hline 78 & 93.6 & 85.1 & 210 & 97 & 99.8 & 60 & 92.1 & 93.1 & 43 \\
\hline 165 & 97.8 & 97.9 & 246 & 100 & 99.1 & 352 & 100 & 99.1 & 346 \\
\hline 166 & 100 & 88.7 & 40 & 100 & 82.2 & 22 & 99.8 & 81.6 & 16 \\
\hline 184 & 99.4 & 88.3 & 72 & 99.4 & 100 & 28 & 98.7 & 99.8 & 85 \\
\hline 185 & 0 & 0 & 0 & 0 & 0 & 0 & 0 & 0 & 0 \\
\hline
\end{tabular}

Table B1. Continued.

\begin{tabular}{lrrr}
\hline \multicolumn{4}{c}{ CAF99 (all classes - LC map) } \\
\hline \multicolumn{4}{c}{2015} \\
\hline Class & PA & UA & NoRP \\
\hline 31 & 91.6 & 99.8 & 267 \\
32 & 94.5 & 100 & 69 \\
56 & 100 & 99.5 & 76 \\
59 & 100 & 9.5 & 4 \\
60 & 91.9 & 96.5 & 125 \\
77 & 99.6 & 99.2 & 732 \\
78 & 79.1 & 91.5 & 156 \\
112 & 96.1 & 95.9 & 341 \\
148 & 98.7 & 96.9 & 168 \\
165 & 97.8 & 97.5 & 240 \\
166 & 100 & 89.2 & 42 \\
171 & 100 & 100 & 102 \\
175 & 0 & 0 & 3 \\
178 & 100 & 91.6 & 77 \\
184 & 100 & 95.9 & 150 \\
185 & 100 & 100 & 2 \\
190 & 100 & 100 & 113 \\
191 & 100 & 100 & 60 \\
\hline
\end{tabular}

Table B1. Continued.

\begin{tabular}{|c|c|c|c|c|c|c|c|}
\hline \multicolumn{8}{|c|}{ CAR01 } \\
\hline \multicolumn{4}{|c|}{ Aggregated classes } & \multicolumn{4}{|c|}{ All classes - LC map } \\
\hline \multicolumn{4}{|c|}{2000} & \multicolumn{4}{|c|}{2017} \\
\hline Class & PA & UA & NoRP & Class & PA & UA & NoRP \\
\hline 3 & 90.8 & 94.5 & 874 & 11 & 91.9 & 86.5 & 79 \\
\hline 4 & 90.1 & 96.1 & 890 & 31 & 83.1 & 83.2 & 110 \\
\hline 6 & 98.8 & 97.3 & 160 & 32 & 98.9 & 84.5 & 65 \\
\hline 7 & 93 & 92.1 & 343 & 33 & 80.6 & 79.8 & 65 \\
\hline 11 & 83.7 & 82.7 & 70 & 34 & 100 & 81.9 & 24 \\
\hline 13 & 99.8 & 83.5 & 155 & 55 & 98.3 & 86.2 & 71 \\
\hline 14 & 89.7 & 93.6 & 181 & 56 & 100 & 92.9 & 87 \\
\hline 77 & 97.9 & 90.6 & 519 & 59 & 91 & 92.3 & 159 \\
\hline 78 & 92.5 & 88.6 & 346 & 60 & 85.8 & 92.2 & 272 \\
\hline 165 & 96 & 89.7 & 61 & 77 & 97.8 & 93.3 & 513 \\
\hline 166 & 100 & 92.3 & 57 & 78 & 89.4 & 88.5 & 332 \\
\hline 184 & 92.5 & 98.1 & 122 & 112 & 90.4 & 93.4 & 379 \\
\hline 185 & 100 & 97.2 & 64 & 116 & 92.3 & 94.6 & 116 \\
\hline 999 & 99.6 & 98.2 & 173 & 148 & 88.5 & 89.5 & 270 \\
\hline & & & & 152 & 100 & 92.8 & 63 \\
\hline & & & & 159 & 96 & 97.5 & 81 \\
\hline & & & & 160 & 82.1 & 97.5 & 85 \\
\hline & & & & 165 & 94.8 & 89.6 & 63 \\
\hline & & & & 166 & 100 & 91.8 & 56 \\
\hline & & & & 171 & 90.7 & 90.9 & 102 \\
\hline & & & & 175 & 93.4 & 95.3 & 85 \\
\hline & & & & 178 & 95.5 & 84.6 & 92 \\
\hline & & & & 182 & 98.9 & 82.6 & 58 \\
\hline & & & & 184 & 92.2 & 99.8 & 209 \\
\hline & & & & 185 & 100 & 97 & 75 \\
\hline & & & & 186 & 96.2 & 93.3 & 71 \\
\hline & & & & 187 & 97.6 & 87.5 & 81 \\
\hline & & & & 190 & 97.5 & 92.7 & 79 \\
\hline & & & & 191 & 87 & 100 & 112 \\
\hline & & & & 999 & 99.7 & 98.2 & 172 \\
\hline
\end{tabular}


Table B1. Continued.

\begin{tabular}{|c|c|c|c|c|c|c|c|}
\hline \multicolumn{8}{|c|}{ EAF04 } \\
\hline \multicolumn{4}{|c|}{ Aggregated classes } & \multicolumn{4}{|c|}{ All classes - LC map } \\
\hline \multicolumn{4}{|c|}{2000} & \multicolumn{4}{|c|}{2017} \\
\hline Class & $\mathrm{PA}$ & UA & NoRP & Class & PA & UA & NoRP \\
\hline 3 & 93.4 & 95 & 638 & 11 & 100 & 98.7 & 86 \\
\hline 4 & 96.8 & 96.3 & 834 & 31 & 100 & 79.4 & 43 \\
\hline 6 & 83 & 82.1 & 130 & 32 & 100 & 100 & 12 \\
\hline 7 & 92.4 & 95.7 & 260 & 33 & 100 & 97.6 & 129 \\
\hline 11 & 100 & 98.7 & 86 & 34 & 90.9 & 99.6 & 97 \\
\hline 14 & 99.5 & 97.9 & 172 & 55 & 100 & 99.8 & 78 \\
\hline 77 & 99.3 & 98.5 & 952 & 56 & 100 & 93.8 & 30 \\
\hline 78 & 97.3 & 98.5 & 723 & 59 & 100 & 100 & 82 \\
\hline 165 & 100 & 100 & 51 & 60 & 96.8 & 94.4 & 269 \\
\hline 166 & 0 & 0 & 2 & 77 & 98.8 & 98 & 922 \\
\hline 184 & 99.6 & 97.4 & 90 & 78 & 96.6 & 98.4 & 652 \\
\hline \multirow[t]{15}{*}{185} & 100 & 83.3 & 5 & 112 & 95.6 & 95.1 & 465 \\
\hline & & & & 116 & 91.3 & 97.8 & 114 \\
\hline & & & & 148 & 99.7 & 94.8 & 135 \\
\hline & & & & 152 & 100 & 77.3 & 17 \\
\hline & & & & 159 & 0 & 0 & 0 \\
\hline & & & & 160 & 93.7 & 99.5 & 138 \\
\hline & & & & 165 & 100 & 100 & 51 \\
\hline & & & & 166 & 0 & 0 & 2 \\
\hline & & & & 171 & 100 & 91 & 35 \\
\hline & & & & 175 & 60.9 & 83.4 & 11 \\
\hline & & & & 178 & 92.3 & 95.1 & 211 \\
\hline & & & & 184 & 99.8 & 100 & 171 \\
\hline & & & & 185 & 100 & 92 & 23 \\
\hline & & & & 190 & 99.8 & 98.9 & 92 \\
\hline & & & & 191 & 100 & 98.5 & 78 \\
\hline
\end{tabular}

Table B1. Continued.

\begin{tabular}{|c|c|c|c|}
\hline \multicolumn{4}{|c|}{ PAC01 (all classes - LC map) } \\
\hline \multicolumn{4}{|c|}{2016} \\
\hline Class & PA & UA & NoRP \\
\hline 11 & 96.4 & 91.1 & 89 \\
\hline 31 & 87.2 & 96.8 & 70 \\
\hline 32 & 94.5 & 85.2 & 50 \\
\hline 33 & 0 & 0 & 1 \\
\hline 34 & 0 & 0 & 1 \\
\hline 55 & 60.8 & 100 & 13 \\
\hline 56 & 99.2 & 96.4 & 29 \\
\hline 60 & 93.1 & 88.1 & 386 \\
\hline 91 & 95.8 & 90.8 & 536 \\
\hline 92 & 83.2 & 87.5 & 236 \\
\hline 95 & 96.5 & 89.2 & 390 \\
\hline 96 & 84.6 & 95.9 & 423 \\
\hline 123 & 89.3 & 78.8 & 132 \\
\hline 124 & 88.9 & 97.8 & 160 \\
\hline 139 & 98.9 & 87.2 & 100 \\
\hline 140 & 96.3 & 89.9 & 113 \\
\hline 148 & 89.5 & 94 & 356 \\
\hline 152 & 0 & 0 & 3 \\
\hline 160 & 92.1 & 94.4 & 140 \\
\hline 165 & 94.1 & 90.4 & 78 \\
\hline 166 & 89 & 98.7 & 75 \\
\hline 171 & 98.4 & 93.4 & 53 \\
\hline 175 & 98.3 & 92.9 & 72 \\
\hline 178 & 95.5 & 95.3 & 212 \\
\hline 182 & 100 & 95.7 & 14 \\
\hline 184 & 91.7 & 96.1 & 234 \\
\hline 185 & 96.3 & 100 & 23 \\
\hline 187 & 96 & 95.3 & 44 \\
\hline 190 & 88.7 & 94.3 & 277 \\
\hline 191 & 100 & 97.3 & 29 \\
\hline 999 & 96.3 & 78 & 61 \\
\hline
\end{tabular}

Table B1. Continued.

\begin{tabular}{|c|c|c|c|c|c|c|c|c|c|}
\hline \multirow[b]{3}{*}{ Class } & \multicolumn{9}{|c|}{ PAC01 (aggregated classes) } \\
\hline & \multicolumn{3}{|c|}{2000} & \multicolumn{3}{|c|}{2005} & \multicolumn{3}{|c|}{2010} \\
\hline & PA & UA & NoRP & PA & UA & NoRP & PA & UA & NoRP \\
\hline 3 & 89.6 & 89.5 & 603 & 87.9 & 89.4 & 602 & 92.2 & 91.5 & 600 \\
\hline 4 & 88.2 & 96.3 & 983 & 88 & 96.2 & 967 & 92 & 95.4 & 908 \\
\hline 6 & 95.9 & 93.9 & 158 & 95.7 & 94.7 & 147 & 94 & 93.6 & 151 \\
\hline 7 & 96.2 & 96.4 & 380 & 95.6 & 96 & 361 & 93.6 & 93.9 & 341 \\
\hline 11 & 81.1 & 88.2 & 86 & 97.7 & 88 & 81 & 93.5 & 88.2 & 87 \\
\hline 13 & 94.1 & 88.9 & 34 & 94.2 & 86.7 & 35 & 96.4 & 93 & 38 \\
\hline 14 & 90.4 & 93.9 & 269 & 91 & 94.8 & 303 & 91.1 & 94.8 & 334 \\
\hline 77 & 98.2 & 91.8 & 713 & 98.2 & 91.2 & 707 & 97.5 & 93.5 & 722 \\
\hline 78 & 92.4 & 95 & 821 & 91.8 & 94.7 & 805 & 92.3 & 95.3 & 811 \\
\hline 165 & 92.6 & 93.7 & 88 & 89.8 & 94.2 & 87 & 92.9 & 93 & 75 \\
\hline 166 & 93.2 & 99.2 & 78 & 90.8 & 98.8 & 75 & 96.7 & 98.8 & 72 \\
\hline 184 & 94.3 & 91.7 & 120 & 94.4 & 93 & 163 & 95 & 96 & 190 \\
\hline 185 & 100 & 94.9 & 12 & 100 & 95.1 & 13 & 97.3 & 100 & 17 \\
\hline 999 & 96.3 & 78 & 61 & 96.3 & 78 & 61 & 96.3 & 78 & 61 \\
\hline
\end{tabular}


Table B1. Continued.

\begin{tabular}{|c|c|c|c|c|c|c|c|}
\hline \multicolumn{8}{|c|}{ SAF21 } \\
\hline \multicolumn{4}{|c|}{ Aggregated classes } & \multicolumn{4}{|c|}{ All classes - LC map } \\
\hline \multicolumn{4}{|c|}{2000} & \multicolumn{4}{|c|}{2017} \\
\hline Class & PA & UA & NoRP & Class & PA & UA & NoRP \\
\hline 3 & 89.5 & 84 & 517 & 11 & 95.3 & 92.8 & 67 \\
\hline 4 & 94.9 & 92.4 & 1352 & 31 & 83.8 & 91.6 & 110 \\
\hline 6 & 75.2 & 80.6 & 269 & 32 & 2.5 & 30.4 & 14 \\
\hline 7 & 84 & 82.7 & 238 & 33 & 25 & 100 & 12 \\
\hline 11 & 95.3 & 94.2 & 68 & 34 & 99.7 & 96.5 & 69 \\
\hline 13 & 89.2 & 98 & 140 & 55 & 98.8 & 97.3 & 75 \\
\hline 14 & 83.2 & 96.4 & 176 & 56 & 100 & 34.1 & 14 \\
\hline 77 & 93 & 97.2 & 856 & 59 & 98.3 & 98.2 & 59 \\
\hline 78 & 87.8 & 82.2 & 228 & 60 & 88.3 & 82.6 & 179 \\
\hline 165 & 100 & 11.9 & 5 & 77 & 94.4 & 96.4 & 692 \\
\hline 166 & 0.4 & 16.7 & 13 & 78 & 88 & 81.8 & 253 \\
\hline 184 & 100 & 76.4 & 81 & 112 & 93 & 88.4 & 725 \\
\hline 185 & 96 & 94.1 & 50 & 116 & 94.3 & 80.7 & 79 \\
\hline \multirow[t]{18}{*}{999} & 0 & 0 & 1 & 148 & 89.8 & 93.8 & 530 \\
\hline & & & & 152 & 84.7 & 85.4 & 47 \\
\hline & & & & 156 & 0 & 0 & 1 \\
\hline & & & & 159 & 100 & 14.7 & 5 \\
\hline & & & & 160 & 76 & 81.5 & 273 \\
\hline & & & & 165 & 100 & 11.9 & 5 \\
\hline & & & & 166 & 0.4 & 16.7 & 13 \\
\hline & & & & 171 & 100 & 79.1 & 84 \\
\hline & & & & 175 & 67.6 & 96.6 & 19 \\
\hline & & & & 178 & 85.5 & 83.5 & 125 \\
\hline & & & & 182 & 12.9 & 66.7 & 3 \\
\hline & & & & 184 & 100 & 94.5 & 153 \\
\hline & & & & 185 & 99.7 & 99.4 & 72 \\
\hline & & & & 186 & 100 & 94.1 & 64 \\
\hline & & & & 187 & 87.9 & 98.6 & 76 \\
\hline & & & & 190 & 79.7 & 97.6 & 99 \\
\hline & & & & 191 & 95.4 & 93.3 & 76 \\
\hline & & & & 999 & 0 & 0 & 1 \\
\hline
\end{tabular}

Table B1. Continued.

\begin{tabular}{|c|c|c|c|c|c|c|c|}
\hline \multicolumn{8}{|c|}{ WAF04 } \\
\hline \multicolumn{4}{|c|}{ Aggregated classes } & \multicolumn{4}{|c|}{ All classes - LC map } \\
\hline \multicolumn{4}{|c|}{2000} & \multicolumn{4}{|c|}{2015} \\
\hline Class & $\mathrm{PA}$ & UA & NoRP & Class & PA & UA & NoRP \\
\hline 3 & 99.5 & 93.7 & 670 & 11 & 100 & 100 & 48 \\
\hline 4 & 97.4 & 98.8 & 1345 & 31 & 100 & 100 & 9 \\
\hline 6 & 91.7 & 84.5 & 67 & 32 & 80 & 100 & 5 \\
\hline 7 & 98.6 & 95.3 & 239 & 33 & 92.8 & 100 & 17 \\
\hline 11 & 100 & 100 & 47 & 34 & 99.1 & 99 & 75 \\
\hline 13 & 97 & 100 & 108 & 60 & 99.5 & 98.1 & 726 \\
\hline 14 & 97.7 & 97.3 & 162 & 77 & 97.9 & 95.2 & 146 \\
\hline 77 & 95.5 & 97.4 & 151 & 78 & 97.1 & 98.3 & 487 \\
\hline 78 & 96 & 98.2 & 537 & 112 & 98.3 & 96.3 & 756 \\
\hline 165 & 100 & 73.3 & 21 & 116 & 86.1 & 98.1 & 297 \\
\hline 166 & 98.6 & 93.7 & 60 & 148 & 83.6 & 98.9 & 90 \\
\hline 184 & 100 & 97.5 & 83 & 152 & 98.7 & 99.5 & 40 \\
\hline 185 & 100 & 100 & 8 & 160 & 81.8 & 89 & 82 \\
\hline & & & & 165 & 100 & 72.4 & 20 \\
\hline & & & & 166 & 98.5 & 92.5 & 59 \\
\hline & & & & 171 & 92.7 & 95 & 59 \\
\hline & & & & 175 & 96.5 & 98.6 & 32 \\
\hline & & & & 178 & 97.3 & 72.5 & 142 \\
\hline & & & & 182 & 100 & 97.5 & 29 \\
\hline & & & & 184 & 100 & 97.8 & 151 \\
\hline & & & & 185 & 100 & 100 & 10 \\
\hline & & & & 187 & 100 & 100 & 79 \\
\hline & & & & 190 & 97.6 & 98.7 & 79 \\
\hline & & & & 191 & 97.7 & 97.3 & 70 \\
\hline
\end{tabular}


Note on former version. A former version of this article was published on 23 November 2020 and is available at https://doi.org/10.5194/essd-12-3001-2020.

Supplement. The supplement related to this article is available online at: https://doi.org/10.5194/essd-13-3767-2021-supplement.

Author contributions. ZSZ, ABB and AL designed the work and wrote the paper.

Competing interests. The authors declare that they have no conflict of interest.

Disclaimer. All features and data are provided "as is" with no warranties of any kind.

Publisher's note: Copernicus Publications remains neutral with regard to jurisdictional claims in published maps and institutional affiliations.

Acknowledgements. Development of the thematic maps was made possible thanks to the efforts of eGEOS (an Italian Space Agency/Telespazio company), ITHACA (Information Technology for Humanitarian Assistance, Cooperation and Action) and Telespazio (a Leonardo and Thales company). The quality evaluations were made possible by IGN FI (France), Joanneum Research (Austria), EOXPLORE (Germany), GISBOX (Romania), Space4environment (Luxembourg), ONFI (France) and LuxSpace (Luxembourg). This work was produced under the European Commission Copernicus Programme, Global Land Service, High Resolution Hot Spot Monitoring component.

Review statement. This paper was edited by David Carlson and reviewed by Nitesh Poona and one anonymous referee.

\section{References}

Brink, A., Eva, H., and Bodart, C.: Is Africa Losing Its Natural Vegetation? Monitoring Trajectories of Land-Cover Change Using Landsat Imagery, in: Remote Sensing of Land Use and Land Cover, Principles and Applications, vol. 20120991, edited by: Giri, C., CRC Press, Boca Raton, Florida, 369-376, https://doi.org/10.1201/b11964-28, 2012.

Brink, A. B. and Eva, H. D.: Monitoring 25 years of land cover change dynamics in Africa: A sample based remote sensing approach, 29, 501-512, https://doi.org/10.1016/j.apgeog.2008.10.004, 2009.

Schulte to Büuhne, H., Wegmann, M., Durant, S. M., Ransom, C., de Ornellas, P., Grange, S., Beatty, H., and Pettorelli, N.: Protection status and national socio-economic context shape land con- version in and around a key transboundary protected area complex in West Africa, 3, https://doi.org/10.1002/rse2.47, 2017.

Di Gregorio, A.: Land cover classification system: classification concepts and user manual: LCCS, Software version 2., Food and Agriculture Organization of the United Nations, Rome, 190 pp., 2005.

Di Minin, E., Slotow, R., Hunter, L. T. B., Montesino Pouzols, F., Toivonen, T., Verburg, P. H., Leader-Williams, N., Petracca, L., and Moilanen, A.: Global priorities for national carnivore conservation under land use change, Sci. Rep., 6, 23814, https://doi.org/10.1038/srep23814, 2016.

European Commission: Science for the AU-EU Partnership building knowledge for sustainable development, Joint Research Centre, 2018.

Foody, G. M.: Valuing map validation: The need for rigorous land cover map accuracy assessment in economic valuations of ecosystem services, Ecol Econom., 111, 23-28, https://doi.org/10.1016/j.ecolecon.2015.01.003, 2015.

Fritz, S., See, L., Perger, C., McCallum, I., Schill, C., Schepaschenko, D., Duerauer, M., Karner, M., Dresel, C., Laso-Bayas, J.-C., Lesiv, M., Moorthy, I., Salk, C. F., Danylo, O., Sturn, T., Albrecht, F., You, L., Kraxner, F., and Obersteiner, M.: A global dataset of crowdsourced land cover and land use reference data, Sci. Data, 4, 1-8, https://doi.org/10.1038/sdata.2017.75, 2017.

Gallaun, H., Steinegger, M., Wack, R., Schardt, M., Kornberger, B., and Schmitt, U.: Remote Sensing Based TwoStage Sampling for Accuracy Assessment and Area Estimation of Land Cover Changes, Remote Sens., 7, 11992-12008, https://doi.org/10.3390/rs70911992, 2015.

Geist, H. J. and Lambin, E. F.: Proximate Causes and Underlying Driving Forces of Tropical Deforestation, BioScience, 52, 143-150, https://doi.org/10.1641/00063568(2002)052[0143:PCAUDF]2.0.CO;2, 2002.

Grafius, D. R., Corstanje, R., Warren, P. H., Evans, K. L., Hancock, S., and Harris, J. A.: The impact of land use/land cover scale on modelling urban ecosystem services, Landscape Ecol., 31, 15091522, https://doi.org/10.1007/s10980-015-0337-7, 2016.

Güneralp, B., Lwasa, S., Masundire, H., Parnell, S., and Seto, K. C.: Urbanization in Africa: challenges and opportunities for conservation, Environ. Res. Lett., 13, 015002, https://doi.org/10.1088/1748-9326/aa94fe, 2017.

Haifeng, H., Jianrong, K., Xiaoke, Z., and Kaiyuan, D.: Atmospheric correction of SPOT satellite images based on radiation transfer model, International Conference on Computer Application and System Modeling (ICCASM 2010), https://doi.org/10.1109/ICCASM.2010.5619149, 2010.

Hugo, G.: Patterns and Trends of Urbanization and Urban Growth in Asia, in: Internal Migration, Urbanization and Poverty in Asia: Dynamics and Interrelationships, edited by: Jayanthakumaran, K., Verma, R., Wan, G., and Wilson, E., Springer, Singapore, 1345, https://doi.org/10.1007/978-981-13-1537-4_2, 2019.

Ide, T., Palmer, L. R., and Barnett, J.: Environmental peacebuilding from below: customary approaches in Timor-Leste, Int. Aff., 97, 103-117, https://doi.org/10.1093/ia/iiaa059, 2021.

Kebede, E., Kagochi, J., and Jolly, C. M.: Energy consumption and economic development in Sub-Sahara Africa, Energ. Econom., 32, 532-537, https://doi.org/10.1016/j.eneco.2010.02.003, 2010.

Lambin, E. F. and Meyfroidt, P.: Inaugural Article: Global land use change, economic globalization, and the loom- 
ing land scarcity, P. Natl. Acad. Sci., 108, 3465-3472, https://doi.org/10.1073/pnas.1100480108, 2011.

Lang, M. and Tychon, B.: Copernicus Global Land Component Product and Service Detailed Technical Requirements Appendix 1 of Technical Annex, https://land.copernicus.eu/global/ documents/applicable (last access: 1 August 2021), 2015.

Lu, D., Mausel, P., Brondizio, E., and Moran, E.: Change detection techniques, Int. J. Remote Sens., 25, 2365-2401, https://doi.org/10.1080/0143116031000139863, 2004.

MacKinnon, J., Aveling, C., Olivier, R., Murray, M., Paolini, C., European Commission, and Directorate-General for International Cooperation and Development: Larger than elephants: inputs for an EU strategic approach to wildlife conservation in Africa: synthesis, European Commission, EU publication MN-02-15-558EN-C, https://doi.org/10.2841/909032, 2015.

Marshall, M., Norton-Griffiths, M., Herr, H., Lamprey, R., Sheffield, J., Vagen, T., and Okotto-Okotto, J.: Continuous and consistent land use/cover change estimates using socio-ecological data, Earth Syst. Dynam., 8, 55-73, https://doi.org/10.5194/esd-8-55-2017, 2017.

Masek, J. G., Vermote, E. F., Saleous, N. E., Wolfe, R., Hall, F. G., Huemmrich, K. F., Gao, F., Kutler, J., and Lim, T.-K.: A Landsat Surface Reflectance Dataset for North America, 19902000, IEEE Geoscience and Remote Sensing Letters, 3, 68-72, https://doi.org/10.1109/LGRS.2005.857030, 2006.

Mora, B., Tsendbazar, N.-E., Herold, M., and Arino, O.: Global Land Cover Mapping: Current Status and Future Trends, in: Land Use and Land Cover Mapping in Europe, vol. 18, edited by: Manakos, I. and Braun, M., Springer Netherlands, Dordrecht, 11-30, https://doi.org/10.1007/978-94-007-7969-3_2, 2014.

Nathaniel, S. P., Nwulu, N., and Bekun, F.: Natural resource, globalization, urbanization, human capital, and environmental degradation in Latin American and Caribbean countries, Environ. Sci. Pollut. Res., 28, 6207-6221, https://doi.org/10.1007/s11356020-10850-9, 2021.

Nissan, H., Goddard, L., de Perez, E. C., Furlow, J., Baethgen, W., Thomson, M. C., and Mason, S. J.: On the use and misuse of climate change projections in international development, WIREs Clim. Change, 10, e579, https://doi.org/10.1002/wcc.579, 2019.

Richter, R., Louis, J., and Müller-Wilm, U.: Sentinel-2 msi - level 2a products algorithm theoretical basis document, Deutsches Zentrum für Luft- und Raumfahrt e.V. (DLR), 72 pp., 2012.

Saah, D., Tenneson, K., Poortinga, A., Nguyen, Q., Chishtie, F., Aung, K. S., Markert, K. N., Clinton, N., Anderson, E. R., Cutter, P., Goldstein, J., Housman, I. W., Bhandari, B., Potapov, P. V., Matin, M., Uddin, K., Pham, H. N., Khanal, N., Maharjan, S., Ellenberg, W. L., Bajracharya, B., Bhargava, R., Maus, P., Patterson, M., Flores-Anderson, A. I., Silverman, J., Sovann, C., Do, P. M., Nguyen, G. V., Bounthabandit, S., Aryal, R. R., Myat, S. M., Sato, K., Lindquist, E., Kono, M., Broadhead, J., Towashiraporn, P., and Ganz, D.: Primitives as building blocks for constructing land cover maps, Int. J. Appl. Earth Observ. Geoinf., 85, 101979, https://doi.org/10.1016/j.jag.2019.101979, 2020.

Stehman, S. V.: Impact of sample size allocation when using stratified random sampling to estimate accuracy and area of land-cover change, Remote Sens. Lett., 3, 111-120, https://doi.org/10.1080/01431161.2010.541950, 2012.

Strobl, P., Baumann, P., Lewis, A., Szantoi, Z., Killough, B., Purss, M. B. J., Craglia, M., Nativi, S., Held, A., and Dhu, T.: The six faces of the data cube, in: Proc. of the 2017 conference on Big Data from Space (BiDS'17), Big Data from Space (BiDS'17), Toulouse, France, 32-35, https://doi.org/10.2760/383579, 2017. Sylla, M. B., Pal, J. S., Wang, G. L., and Lawrence, P. J.: Impact of land cover characterization on regional climate modeling over West Africa, Clim. Dyn., 46, 637-650, https://doi.org/10.1007/s00382-015-2603-4, 2016.

Szantoi, Z., Escobedo, F., Abd-Elrahman, A., Smith, S., and Pearlstine, L.: Analyzing fine-scale wetland composition using high resolution imagery and texture features, Int. J. Appl. Earth Observ. Geoinf., 23, 204-212, https://doi.org/10.1016/j.jag.2013.01.003, 2013.

Szantoi, Z., Brink, A., Buchanan, G., Bastin, L., Lupi, A., Simonetti, D., Mayaux, P., Peedell, S., and Davy, J.: A simple remote sensing based information system for monitoring sites of conservation importance, Remote Sens. Ecol. Conserv., 2, 16-24, https://doi.org/10.1002/rse2.14, 2016.

Szantoi, Z., Geller, G. N., Tsendbazar, N.-E., See, L., Griffiths, P., Fritz, S., Gong, P., Herold, M., Mora, B., and Obregón, A.: Addressing the need for improved land cover map products for policy support, Environ. Sci. Pol., 112, 28-35, https://doi.org/10.1016/j.envsci.2020.04.005, 2020a.

Szantoi, Z., Brink, A., Lupi, A., Mammone, C., and Jaffrain, G.: Key landscapes for conservation land cover and change monitoring, thematic and validation datasets for sub-Saharan Africa, Earth Syst. Sci. Data, 12, 3001-3019, https://doi.org/10.5194/essd-12-3001-2020, 2020 b.

Szantoi, Z., Brink, A., and Lupi, A.: Land cover and change thematic and validation datasets for selected African, Caribbean and Pacific areas, Pangaea, https://doi.pangaea.de/10.1594/PANGAEA.931968, 2021a.

Szantoi, Z., Brink, A., and Lupi, A.: Land cover and change thematic and validation datasets for selected African, Caribbean and Pacific areas [Data set], Zenodo, https://doi.org/10.5281/ZENODO.4621375, 2021 b.

Szantoi Z., Jaffrain, G., Gallaun, H., Bielski, C., Ruf, K., Lupi, A., Miletich, P., Giroux, A.C., Carlan, I., Croi, W., Augu, H., Kowalewski, C., and Brink, A.: Quality assurance and assessment framework for large area land cover maps validation in the Copernicus high resolution hot spot monitoring activity, Eur. J. Remote Sens., accepted, 2021c.

Tewkesbury, A. P., Comber, A. J., Tate, N. J., Lamb, A., and Fisher, P. F.: A critical synthesis of remotely sensed optical image change detection techniques, Remote Sens. Environ., 160, 1-14, https://doi.org/10.1016/j.rse.2015.01.006, 2015.

Tolessa, T., Senbeta, F., and Kidane, M.: The impact of land use/land cover change on ecosystem services in the central highlands of Ethiopia, Ecosystem Services, 23, 47-54, https://doi.org/10.1016/j.ecoser.2016.11.010, 2017.

Tsendbazar, N.-E., Herold, M., de Bruin, S., Lesiv, M., Fritz, S., Van De Kerchove, R., Buchhorn, M., Duerauer, M., Szantoi, Z., and Pekel, J.-F.: Developing and applying a multi-purpose land cover validation dataset for Africa, Remote Sens. Environ., 219, 298-309, https://doi.org/10.1016/j.rse.2018.10.025, 2018.

UNEP-WCMC and IUCN: Protected Planet: The World Database on Protected Areas (WDPA) and World Database on Other Effective Area-based Conservation Measures (WD-OECM), available at: https://www.protectedplanet.net/en, last access: March 2021. 
van der Meer, E.: Carnivore conservation under land use change: the status of Zimbabwe's cheetah population after land reform, Biodiv. Conserv., 27, 647-663, https://doi.org/10.1007/s10531017-1455-0, 2018.
Vondou, D. A. and Haensler, A.: Evaluation of simulations with the regional climate model REMO over Central Africa and the effect of increased spatial resolution, Int. J. Climatol, 37, 741760, https://doi.org/10.1002/joc.5035, 2017. 